ERIKA M. SANTANA

Causas e consequências da poliandria

Causes and consequences of polyandry

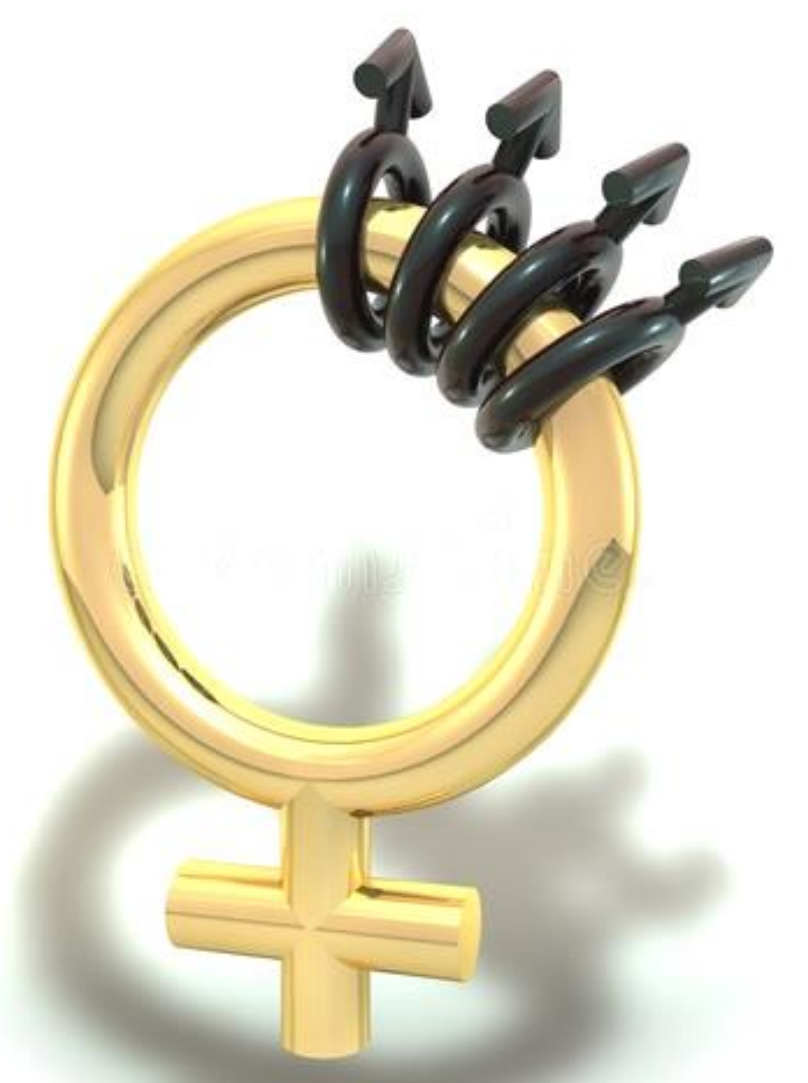

SÃo PAUlO

2018 


\section{Causas e consequências da poliandria}

\section{Causes and consequences of polyandry}

Tese apresentada ao Instituto de Biociências da Universidade de São Paulo como parte dos requisitos para obtenção do título de Doutor em Ciências, na área de Ecologia de Ecossistemas Terrestres e Aquáticos.

Orientador: Glauco Machado

Departamento de Ecologia, Universidade de São Paulo, Brasil

SÃO PAULO

2018 
Autorizo a reprodução e divulgação total ou parcial deste trabalho, por qualquer meio convencional ou eletrônico, para fins de estudo e pesquisa, desde que citada a fonte.

Santana, Erika M.

Causas e consequências da poliandria / Erika M. Santana; orientador Glauco Machado. --. São Paulo, 2018.

$100 \mathrm{f}$.

Tese (Doutorado) - Instituto de Biociências da Universidade de São Paulo. Departamento de Ecologia.

1. seleção sexual. 2. competição espermática. 3. qualidade do macho. 4. plasticidade fenotípica. 5. armamentos masculinos.

1. Universidade de São Paulo. Instituto de Biociências.

Departamento de Ecologia. II. Título. 


\section{Agradecimentos}

Ninguém desenvolve um projeto de pesquisa sozinho. Mais que isso, ninguém desenvolve conhecimento acadêmico sozinho. Tornar-se pesquisador e/ou professor é resultado de todas as interações e aprendizados que temos ao longo da pós-graduação. Nos últimos quatro anos, contei com a ajuda, os ensinamentos, as dicas e o suporte, tanto acadêmico quanto psicológico, de diversos amigos, colegas e familiares. Pode parecer clichê, mas nada teria sido possível sem essas pessoas. Abaixo, vou tentar resumir o quanto sou grata a cada uma delas, e espero mesmo não esquecer ninguém.

Primeiramente, gostaria de agradecer aos meus pais, que são a minha base. Ao incentivo, ao companheirismo e aos puxões de orelha da minha mãe; ao apoio e ao orgulho que meu pai tem de mim. Por cada jantar na mesa quando eu voltava de São Paulo, por cada carona até o ponto de ônibus onde eu pegava o fretado de madrugada... Por tudo e por mais um pouco. Muito obrigada, véios!

Ao Paulo, meu companheiro. A única testemunha de todas as minhas oscilações e inseguranças. Ele é a família que eu escolhi, a família que me escolheu. Aquela que formamos juntos. Muito obrigada por sempre me incentivar a acreditar em mim mesma.

Às minhas amigas tão doidas, fortes, decididas e intensas quanto eu: Giselle, Mayara, Joice e Renata Por todos os momentos de risadas (algumas brigas), pelo aprendizado, pelos porres e pelos papos sem noção no whatsapp. Obrigada por estarem lá, por fazerem parte da minha loucura.

Agora vamos adentrar os portões da universidade. Gostaria de começar agradecendo a todos os funcionários do Instituto de Biociências da USP, que sempre foram muito solícitos e gentis. Gostaria de agradecer em particular ao Luis e ao Wellington, por sempre me ajudarem com impressões e questões técnicas. Porém, quero deixar um agradecimento super especial para a Vera, esta santa criatura, que tal qual um guru está sempre disposta a nos ajudar, provendo soluções e dicas para todas as dúvidas que temos sobre as burocracias da vida na pós. Vera, você me ajudou (ou 
seria "me salvou"?) mais de uma vez, e eu não poderia escrever esta seção sem agradecer por toda a sua dedicação. Super obrigada!

Ainda na categoria "funcionários da USP", gostaria de agradecer a todos os professores com os quais aprendi, seja quando cursei disciplinas, participei de monitoria ou assisti palestras. Em especial, gostaria de agradecer ao Paulo Inácio e ao Miúdo, pelas dicas acadêmicas e por sempre estarem dispostos a ajudar e tirar dúvidas.

Já que estamos falando de professores, vou dar um pulo para fora da USP, direto para o exterior. Gostaria de agradecer ao Dr. Leigh Simmons por ter aberto as portas do seu laboratório para me receber, ainda que não tenha sido possível que eu fosse para lá. Gostaria também de agradecer ao Daniel Caetano (Musgo), pelas explicações sobre análises filogenéticas, e ao Bruno Buzatto, pela ajuda em várias etapas do projeto, por ter me recebido em sua casa na Austrália e por ter feito a ponte entre mim e tantos professores incríveis no exterior. Em especial, gostaria de agradecer ao Michael Kasumovic por aceitar orientar a pesquisa que realizei no primeiro capítulo desta tese. Michael, obrigada pela recepção, simpatia, confiança e apoio.

Já que fui até a Austrália, quero agradecer aos amigos incríveis que conheci por lá. Contextualizando: ainda no Brasil, os estudantes de doutorado que receberam a bolsa de estágio no exterior da Coordenação de Aperfeiçoamento de Pessoal de Nível Superior (CAPES) fizeram um grupo no whatsapp para trocar informações. Mais tarde, este grupo se tornou um meio de encontrar doutorandos que estavam na mesma cidade e situação que eu. Dessa forma meio torta, conheci aqueles que seriam minha família em Sydney: Tati, Pri, Renan, Bruno, Lorena, Ricardo, Eduardo e Fábio. Aos meus queridos Team Jovens de Sydney, muito obrigada por estarem lá, comigo e para mim, quando todos os meus amores estavam do outro lado do globo.

Aproveito esta parte do texto para agradecer à CAPES, tanto pela bolsa de doutorado pleno quanto pela bolsa do Programa de Doutorado-sanduíche no Exterior (PDSE) que me permitiu passar 4 meses na Austrália. Esta, sem dúvida, foi a experiência mais maravilhosa que eu já tive na vida.

Ainda na Austrália, obrigada aos professores Shinichi Nakagawa e Russel Bonduriansky por permitirem que eu participasse das reuniões de discussão de artigos 
de seus laboratórios, e aos colegas que participavam das reuniões. Aprendi muito com todos vocês. Por fim, um agradecimento especial ao Justin, à Sam e à Cat pela amizade e simpatia.

Voltando à USP e falando em amizade, gostaria de agradecer a todos os amigos com os quais participei de atividades extra-curriculares na pós, incluindo a EcoEscola, EcoEncontros e Café Existencial. Quero deixar um agradecimento especial para o Bruno, a Camila, a Ayana, o Victor, a Julia, a Jéssica, a Vivian e a Pamela. Muito obrigada pelo companheirismo, aprendizado e risadas. Conviver e trabalhar com vocês foi uma experiência incrível.

Gostaria de agradecer também a todos os membros da Lage pelas trocas acadêmicas, pelos papos no puxadinho e no próprio laboratório. Agradeço em especial aos membros do SexLab: VP, Vinicius (dos sapinhos com miçangas), Vinicius (o vida loka), Louise, Soly, Cris, Andrés, Rosa, Edu, Lygia, Natcho, Pietro, João e Bruna. Obrigada por todos os momentos divertidíssimos no puxadinho e em retiros, pelas dicas e ensinamentos, pelas discussões de artigo enriquecedoras. Boa parte do prazer que tive em fazer o doutorado esteve na convivência com vocês.

Deixei dois agradecimentos especiais para o fim. O primeiro é o agradecimento que quero fazer ao Danilo Muniz. Danilo, eu faço piada o tempo todo, mas realmente não consigo imaginar como poderei retribuir tudo que você fez por mim nesses anos de doutorado. Muito obrigada por toda a imensa ajuda com o projeto, com os textos, com o embasamento teórico e, principalmente, com as análises. Mais que isso, obrigada pelos chacoalhões verbais, por me lembrar sempre que tenho que parar de me desmerecer. A gente nunca sabe como falar essas coisas, né? Mas sua ajuda foi muito importante para mim.

Por fim, eu quero agradecer ao meu orientador. Glauco, é difícil saber por onde começar a agradecer você. Se for para partir do princípio, começo então agradecendo àquele dia no Seu Bobó, em um café pós-almoço ainda no primeiro mês do meu mestrado, no qual você praticamente me intimou a fazer o curso de campo. Você não me conhecia, não além das entrevistas dos dois exames de ingresso que fiz. Mas ali você demonstrou preocupação comigo, com o quanto eu precisava aprender para me tornar uma pesquisadora. Entre este dia e o momento atual, poderia listar inúmeras 
outras ocasiões e motivos para agradecer, mas seria me estender demais. Sendo assim, me limitarei a algumas coisas. Obrigada por aceitar me orientar e pela excelente orientação. Obrigada por acreditar na minha capacidade. Obrigada por todas as reuniões individuais, pela paciência e pela insistência. Saio do doutorado muito mais madura e confiante do que entrei. Grande parte disso, devo a você. Muito obrigada! 


\section{Resumo}

SANTANA, E.M. Causas e consequências da poliandria. 2018. Tese (Doutorado) Instituto de Biociências, Universidade de São Paulo, São Paulo.

De acordo com o paradigma Darwin-Bateman, fêmeas não ganham benefícios em copular com múltiplos machos (i.e., poliandria), dado que seu sucesso reprodutivo depende principalmente da qualidade dos seus parceiros sexuais. Porém, a poliandria é um comportamento amplamente encontrado nas espécies com reprodução sexuada. $\mathrm{O}$ objetivo central desta tese foi explorar as possíveis causas e consequências da poliandria. No Capítulo 1, utilizamos experimentos em laboratório para investigar como a experiência social antes e depois da maturação influencia o grau de poliandria. A espécie estudada foi o grilo australiano Teleogryllus commodus, para a qual o ambiente acústico antes da maturação determina o comportamento reprodutivo das fêmeas após a maturação. Nossos resultados mostram que o grau de poliandria não varia entre fêmeas criadas em dois ambientes acústicos distintos, um composto por machos de qualidade variada (QV) e outro composto por machos de alta qualidade (AQ). As fêmeas do grupo AQ foram menos responsivas aos machos de alta qualidade e aceitaram machos independentemente de sua qualidade, um padrão diferente daquele encontrado para as fêmeas do grupo QV. Quando a qualidade média dos machos encontrados pelas fêmeas do grupo QV foi baixa, o número total de machos aceitos foi baixo, porém quando a qualidade média dos machos foi alta, o número de machos aceitos foi alto. Portanto, há uma interação entre a experiência social antes e após a maturação na determinação do grau de poliandria. No Capítulo 2, utilizamos métodos comparativos para testar se o risco de competição espermática promovido pela poliandria determina a evolução de características masculinas relacionadas à monopolização de fêmeas. Nosso modelo de estudo foram rãs da subfamília Leptodactylinae, cujas espécies podem depositar ovos na água (onde o risco de competição espermática é alto) ou dentro de tocas na terra (onde o risco de competição espermática é baixo). Encontramos que há correlação entre o tipo de local de reprodução (aquático x terrestre) e quatro características masculinas relacionadas à monopolização de fêmeas. Nossos resultados provêem uma relação causal entre características dos machos e a reprodução terrestre, mas os padrões encontrados nem sempre seguiram as previsões propostas pela hipótese de que o risco de competição espermática é menor em espécies com reprodução terrestre. Tais resultados sugerem que as pressões seletivas que agem nas quatro características masculinas exploradas aqui não são as mesmas, provavelmente devido a diferenças nas funções que cada característica tem durante as interações inter- e intra-sexuais. Ao fim desta tese, fornecemos evidências de uma nova causa da poliandria, além de mostrarmos as consequências da poliandria sobre a evolução de características dos machos.

Palavras-chave: ambiente social, armamento masculino, competição espermática, histórico de acasalamento, plasticidade fenotípica, qualidade do macho, taxa de acasalamento de fêmeas. 


\section{Abstract}

SANTANA, E.M. Causes and consequences of polyandry. 2018. Tese (Doutorado) Instituto de Biociências, Universidade de São Paulo, São Paulo.

According to the Darwin-Bateman paradigm, females derive no benefit from multiple mating (i.e., polyandry) and their reproductive success is mainly influenced by the quality of their partners. However, there is increasing evidence that polyandry is ubiquitous across many animal groups. The main goal of this thesis was to explore possible causes and consequences of polyandry. In Chapter 1, we conducted an experiment to investigate how the social experience pre- and post-maturity influences the degree of polyandry. We studied the Australian cricket Teleogryllus commodus, for which we know that the acoustic environment prior to maturity alters female reproductive behavior after maturity. We found that the degree of polyandry did not differ between females reared in two acoustic environments, one composed of varied-quality (VQ) males and other composed of only high-quality (HQ) males. However, whereas females from the HQ group were less responsive to high quality male calls, accepting males regardless of their quality, females from the VQ group showed a different response. When the mean male quality experienced by a female from the VQ group was low, the total number of accepted males was low, and when the mean male quality was high, the total number of accepted males was high. Thus, the social experience pre- and post-maturation interact to determine the degree of polyandry in females of the Australian cricket. In Chapter 2, we used comparative methods to test if the risk of sperm competition promoted by polyandry drives the evolution of male traits related to female monopolization. We studied frogs of the subfamily Leptodactylinae, which lay eggs either on the water (where sperm competition risk is high) or inside terrestrial burrows (where sperm competition risk is low). We found evidence of an evolutionary correlation between the type breeding site (aquatic x terrestrial) and four male traits related to female monopolization. Our study creates a causal link between male traits and terrestrial reproduction, but the patterns not always followed the hypothesis that sperm competition risk is lower in terrestrial breeders. This finding suggests that the selective pressure acting on male traits is not the same, probably because they have different functions during inter- and intrasexual interactions. In conclusion, we provide evidence of a new cause of polyandry and show that polyandry may have consequences for the evolution of weaponry traits in males.

Key-words: female mating rate, male quality, male weaponry, mating history, sexual selection, socially-cued phenotypic plasticity, sperm competition. 


\section{Índice}

Introdução Geral

01

Capítulo 1. Social experience pre- and post-maturation influences the degree of polyandry of a highly promiscuous insect 10

Abstract 11

$\begin{array}{ll}\text { Introduction } & 12\end{array}$

$\begin{array}{ll}\text { Materials and methods } & 14\end{array}$

$\begin{array}{ll}\text { Preparation of individuals } & 14\end{array}$

Calling treatments $\quad 15$

Mating trials $\quad 15$

$\begin{array}{ll}\text { Statistical analyses } & 17\end{array}$

Results 18

$\begin{array}{ll}\text { Polyandry } & 18\end{array}$

$\begin{array}{ll}\text { Post-copulatory decisions } & 19\end{array}$

Discussion 20

Conclusions 24

References $\quad 25$

Supplementary Material $\quad 29$

Capítulo 2. Influence of breeding site type on the sexual selection acting on pre-mating male traits in a clade of Neotropical frogs

Introduction $\quad 37$

Materials and methods $\quad 40$

Study group $\quad 40$

Data collection $\quad 43$

Correlated evolution analysis $\quad 44$

Results $\quad 46$

Discussion $\quad 53$

References $\quad 58$

Supplemental Material $\quad 66$

$\begin{array}{ll}\text { Conclusão Geral } & 81\end{array}$ 


\section{Introdução Geral}

Esta é uma tese sobre sexo. Alguns podem achar que fazer pesquisa sobre sexo no mundo natural seja uma mistura de Laura Muller com National Geographic, ou uma combinação de curiosidade, fofoca, erotismo e voyerismo animal. Bom, pelo menos é isso que meus familiares e amigos não-biólogos pensam quando digo que estudo sexo. Dessa forma, decidi que a introdução e a conclusão desta tese seriam redigidas especialmente para eles, os leitores não-biólogos. Ao longo do texto, pretendo deixar claro como e por que respostas sobre questões relacionadas ao sexo são importantes para entendermos o surgimento de muitas características morfológicas e comportamentais dos organismos. Espero demonstrar também como nem sempre é simples prever os efeitos do sexo na biologia dos organismos, mesmo para naturalistas renomados. Ao terminar a leitura, espero que você, caro leitor, tenha uma visão mais ampla, talvez menos sexy, do sexo no mundo natural. Mas vamos começar do início, citando o naturalista mais famoso que conhecemos, Sir Charles Darwin.

Quase todo mundo (e, com certeza, todo biólogo), sabe quem foi Charles Darwin. No seu livro intitulado "A Origem das Espécies"1, publicado em 1859, Darwin revolucionou a forma como entendemos o mundo ao propor a teoria da evolução das espécies por seleção natural. O que poucos sabem é que, em 1871, ele publicou outro livro intitulado “A Descendência do Homem e Seleção em Relação ao Sexo”². Neste segundo livro, Darwin relata que, em muitas espécies, alguns indivíduos (especialmente os machos) possuem características exageradas que não provêm nenhuma vantagem para a sobrevivência, podendo inclusive ser custosas ao reduzir a habilidade de fuga de predadores e a eficiência na obtenção de alimentos. Talvez o exemplo mais conhecido seja a cauda do pavão que, apesar de ser uma das mais belas estruturas do mundo animal, faz com que os machos sejam presas fáceis para seus predadores. O dilema que atormentou Darwin e para o qual ele não tinha uma resposta convincente quando da publicação do seu primeiro livro era: como características que diminuem a sobrevivência dos machos podem ter evoluído por seleção natural? A

${ }^{1}$ Darwin, C. (1859) The origin of species. London: John Murray.

2 Darwin, C. (1871) The descent of man and selection in relation to sex. London: John Murray. 
resposta a esta e outras perguntas só veio no seu segundo livro, quando ele propôs a teoria da seleção sexual.

Mas exatamente o que é e como funciona essa tal de seleção sexual? Formalmente, a seleção sexual se refere a diferenças não aleatórias no sucesso dos indivíduos de uma espécie em conseguir parceiros e gerar filhotes. Complicado? Bem, imagine uma espécie em que machos e fêmeas sejam iguais em relação à sua morfologia externa e ao seu comportamento. Imagine agora que, devido a mutações genéticas sofridas ao acaso, um macho desenvolva uma característica específica que traga vantagens na disputa por fêmeas. Como exemplo, podemos pensar em chifres que ajudam um macho a afastar machos rivais e, desta forma, monopolizar o acesso às fêmeas. A mutação genética que promoveu o surgimento de chifres nos machos confere vantagem não apenas na obtenção de parceiras sexuais, mas também na sobrevivência, pois os chifres podem ser usados para afugentar predadores. Ao longo do tempo, machos com chifres maiores ou mais fortes sobreviverão melhor, monopolizarão mais fêmeas e deixarão mais filhotes do que machos com chifres pequenos ou mais fracos. A disputa entre machos pelo acesso às fêmeas é o primeiro componente que Darwin reconheceu como sendo parte do processo de seleção sexual. Tal disputa favorece o surgimento de estruturas que conhecemos como armamentos, pois são usadas principalmente em combates entre machos pelo acesso às fêmeas.

O outro processo de seleção sexual reconhecido por Darwin é a escolha de parceiros sexuais pelas fêmeas. É a preferência feminina por características ornamentais masculinas que explica a evolução da cauda do pavão. Segundo Darwin, fêmeas teriam uma predileção inata por ornamentos vistosos e se acasalariam preferencialmente com machos que possuem ornamentos maiores, mais coloridos ou mais elaborados. No final do século XIX, a ideia de que as fêmeas eram um agente importante de seleção sobre características masculinas foi mal recebida não apenas pela sociedade como também pelos pesquisadores. Foi somente na primeira metade do século XX que a escolha feminina voltou a ser estudada e que a hipótese de uma "predileção inata por ornamentos vistosos" foi substituída pela existência de genes que controlam a preferência das fêmeas por características masculinas. Hoje, por exemplo, sabemos que tais genes existem e que os filhotes do sexo feminino herdam os genes de 
preferência de suas mães. Ainda não compreendemos bem como tais genes surgiram e quais são as vantagens que as fêmeas adquirem ao copular com machos mais ornamentados. De qualquer forma, o padrão geral é bem conhecido: machos com ornamentos mais elaborados conseguem mais cópulas do que machos com ornamentos menos elaborados e esta vantagem supera eventuais custos que ornamentos exagerados podem trazer para a sobrevivência dos machos.

Em resumo, tanto a presença de armamentos (tais como chifres) como de ornamentos (tais como a cauda do pavão) aumentam o sucesso de acasalamento dos machos, ou seja, a probabilidade dos machos deixarem filhotes. Um macho com armamento ou ornamento desenvolvido não só deixará mais filhotes, como também seus filhotes machos herdarão as características do pai. Adicionalmente, se quanto maior for o chifre ou a cauda de um macho, mais fêmeas tal macho conseguir fecundar, o resultado esperado é que, ao longo do tempo, só haja machos com chifres ou caudas longas na população. Machos com chifres ou caudas pequenos podem se sair melhor em atividades como conseguir alimento, se esconder ou fugir de predadores. Entretanto, como machos com chifre grandes monopolizam mais fêmeas e machos com cauda longa são preferidos pelas fêmeas, machos com chifre ou cauda pouco desenvolvidos não deixam filhotes e os genes que determinam o tamanho reduzido destas duas estruturas desaparecem da população.

A competição entre machos pelo acesso às fêmeas e a escolha de parceiros sexuais pelas fêmeas são, portanto, os dois mecanismos descritos por Darwin para explicar como a seleção sexual ocorre. Apesar de ter dado o pontapé inicial, Darwin não foi muito além disso, pois suas ideias sobre seleção sexual encontraram uma enorme resistência dentro e fora da academia. O próximo grande passo na nossa compreensão sobre o sexo no mundo natural ocorreu em 1948, quando o geneticista Angus John Bateman publicou os resultados de seus experimentos de acasalamento feitos com moscas de fruta ${ }^{3}$. Bateman identificou cada mosca e registrou o número de cópulas por indivíduo (voyerismo animal, lembram?), o número de filhotes por indivíduo e a habilidade dos filhotes produzidos em competirem com os outros por comida. Bateman descobriu que: (1) quanto mais os machos copulavam, mais filhotes eles 
deixavam; (2) copular mais não aumentava o número de filhotes produzidos pelas fêmeas; (3) alguns machos conseguiam copular muito mais e ter muito mais filhotes que outros; (4) diferentemente dos machos, as fêmeas variavam pouco na quantidade de cópulas e no número de filhotes produzidos ao longo da vida; (5) quando as fêmeas puderam escolher com qual macho copular, seus filhotes eram mais habilidosos em competir por comida do que os filhotes de fêmeas que copularam aleatoriamente com machos sorteados por Bateman. Baseado nos resultados de seus experimentos, Bateman chegou a algumas conclusões gerais sobre o comportamento sexual de machos e fêmeas.

Machos produzem grandes quantidades de gametas pequenos (espermatozóides), ou seja, células reprodutivas que necessitam de pouca quantidade de energia para serem produzidas. Fêmeas, por sua vez, produzem poucos gametas grandes (óvulos), custosos para se produzir. Sendo assim, a taxa reprodutiva potencial dos machos é maior, o que significa que machos têm potencial para deixar muito mais filhos por unidade de tempo do que as fêmeas. Além disso, o sucesso reprodutivo de machos depende somente do seu sucesso de acasalamento: quanto maior for o número de fêmeas com quem um macho copular, mais filhotes ele produzirá. Por isso, machos deveriam ser promíscuos e competir entre si pelo acesso às fêmeas. Fêmeas, por sua vez, têm menor taxa reprodutiva potencial, pois a produção de seus gametas é custosa e demorada. Logo, seu sucesso reprodutivo depende da qualidade do macho com o qual ela copula. Assim, fêmeas deveriam escolher bem com quem copular e não teriam por que serem promíscuas. Essa atribuição de papéis sexuais para machos e fêmeas é chamada de paradigma Darwin-Bateman (Figura 1) e foi um dos avanços mais importantes no entendimento de como a seleção sexual age sobre os organismos em geral.

Porém, nem tudo são flores e, na ciência, estamos sempre descobrindo fatos que nos fazem revisar as teorias vigentes. Por volta de 1980, as técnicas de biologia molecular e os testes de paternidade se tornaram acessíveis e os pesquisadores puderam testar a paternidade dos filhotes não só em um humanos, mas em várias outras espécies de animais. Qual não foi a surpresa da comunidade científica ao perceber que entre os filhotes de aves supostamente monogâmicas havia um monte de 
bastardinhos!? Mais especificamente, em 90\% das espécies de aves consideradas monogâmicas foram encontrados filhotes que não eram dos pais que os criavam. E não é só isso! Mesmo nas espécies majoritariamente monogâmicas, cerca de $11 \%$ dos filhotinhos eram de outros machos ${ }^{4}$. Sendo assim, contrariando o paradigma DarwinBateman, fêmeas da maioria das espécies de aves estavam copulando com mais de um (as vezes vários) machos durante seu período reprodutivo. No jargão técnico, essas fêmeas são conhecidas como poliândricas (poli $=$ muitos, andros $=$ macho).

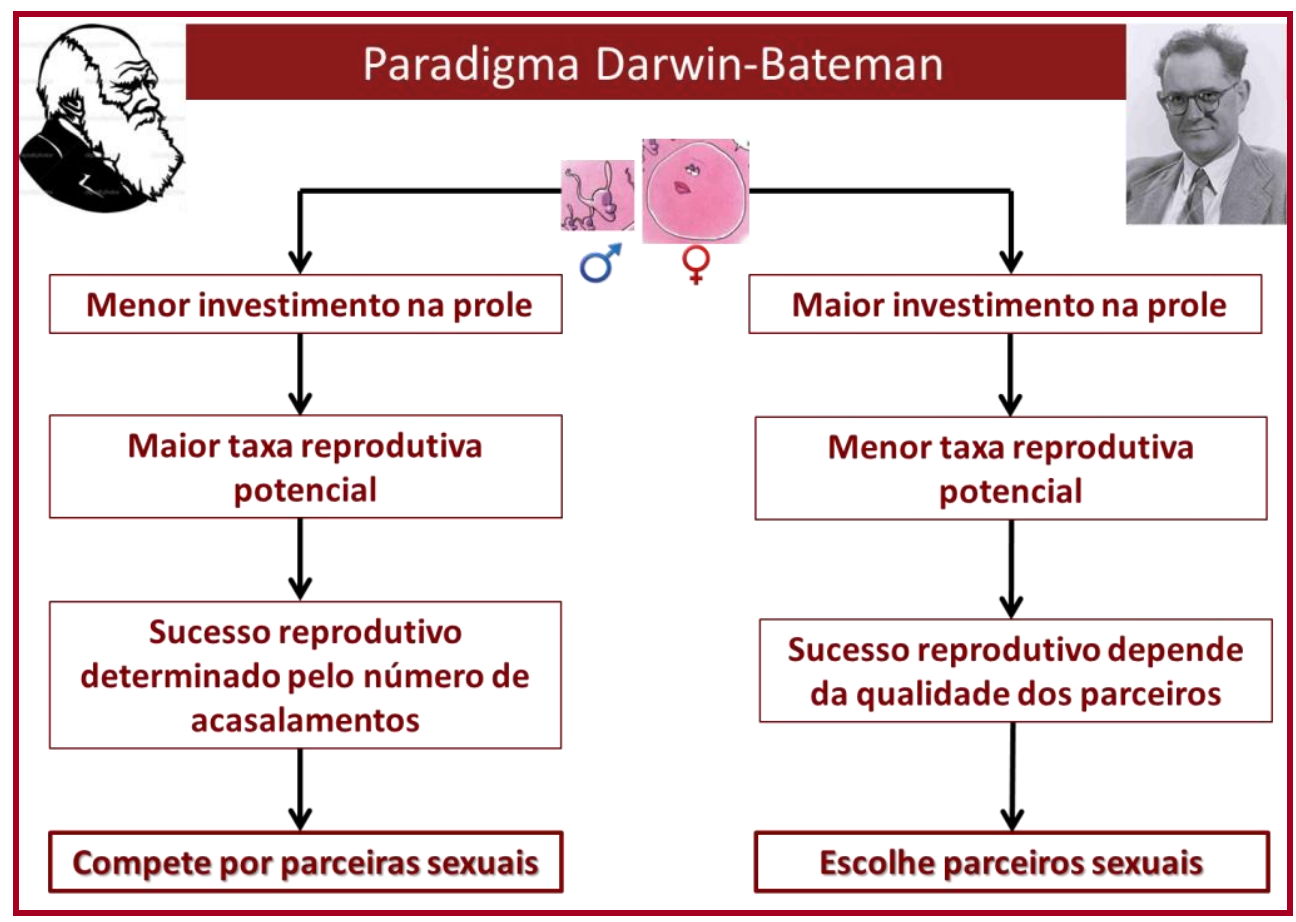

Figura 1. Esquema lógico do paradigma Darwin-Bateman. A partir de diferenças iniciais no tamanho dos gametas, temos uma cascata de eventos que influenciam o comportamento sexual de machos e fêmeas. Durante a produção de gametas, fêmeas investem muita energia em poucos gametas imóveis. Machos, por sua vez, investem menos por gameta, produzindo grandes quantidades de gametas móveis. Esta diferença no investimento em gametas faz com que machos tenham o potencial de deixar um número muito maior de filhotes ao longo da vida do que fêmeas, ou seja, possuam uma maior taxa reprodutiva potencial. Sendo assim, o sucesso reprodutivo de machos depende do número de fêmeas que eles conseguem fecundar. Já o sucesso reprodutivo das fêmeas depende da qualidade do parceiro que irá fecundar seus caros gametas. Por isso, espera-se que machos compitam entre si pelo acesso às fêmeas, enquanto fêmeas devem escolher de forma criteriosa os pais de seus filhotes.

${ }_{4}$ Griffith, S.C., Owens, I.P.F., Thuman, K.A. (2002) Extra pair paternity in birds: a review of interspecific variation and adaptative function. Molecular Ecology, 11:2195-2212. 
Após as descobertas com aves, o número de estudos que encontraram poliandria nas fêmeas só cresceu. Em 2013, uma importante revista científica lançou uma edição inteira só com artigos explorando as implicações da poliandria para pesquisas sobre evolução por seleção sexual ${ }^{5}$. No ano seguinte, um artigo de revisão confirmou que a poliandria é amplamente encontrada em várias espécies animais, incluindo invertebrados e vertebrados 6 . Porém, o número de fêmeas poliândricas em cada população e a quantidade de machos com que cada uma delas copula varia bastante, tanto entre diferentes espécies como dentro de populações da mesma espécie ${ }^{3}$. Na prática, isso significa que é possível encontrar na natureza fêmeas monogâmicas, pouco poliândricas ou muito poliândricas. Além de lançar dúvidas sobre a validade do paradigma Darwin-Bateman (ou seja, "machos competem e fêmeas escolhem"), a avalanche de informações sobre poliandria trouxe consigo duas perguntas inquietantes:

(1) Por que as fêmeas são poliândricas?

(2) Quais as vantagens que levaram à evolução da poliandria?

As perguntas acima vêm sendo exploradas e respondidas ao longo dos últimos dez anos, ou seja, estamos apenas no início de uma longa jornada científica. Já sabemos, porém, que a poliandria pode aumentar a variabilidade genética da prole, gerando filhotes mais resistentes às adversidades do ambiente, incluindo o ataque de parasitas. A poliandria também é vantajosa quando machos oferecem comida em troca de sexo, já que quanto mais parceiros sexuais uma fêmea tiver, mais recursos alimentares ela poderá acumular. Há espécies em que machos matam os filhotes de outros machos, tanto para eliminar os descendentes de um rival como para fazer com que fêmeas entrem no cio novamente. Como forma de evitar o assassinato de filhotes, fêmeas copulam com vários machos do bando e geram dúvidas sobre quem é o verdadeiro pai dos filhotes - dessa forma, elas contêm o instinto assassino dos machos. Fêmeas podem também aceitar copular com machos insistentes ou assediadores quando o esforço para tentar afastá-los é alto, um comportamento

\footnotetext{
${ }^{5}$ Pizzari, T., Wedell, N. (2013) The polyandry revolution. Philosophical Transactions of the Royal Society $B$, Volume 368, Issue 1613.

6 Taylor, M.L., Price, T.A.R., Wedell, N. (2014) Polyandry in nature: a global analysis. Trends in Ecology E Evolution, 29:376-383.
} 
conhecido como poliandria de conveniência. Por fim, contrariando o que se imaginava, a produção de esperma parece não ser ilimitada. Machos podem não ter esperma suficiente para fecundar todos os gametas das fêmeas, especialmente se eles já copularam com muitas outras fêmeas ou se estão debilitados fisicamente. Nesses casos, o sucesso reprodutivo das fêmeas passa a depender, em parte, do número de machos com os quais elas copularam, pois será necessário acumular esperma de muitos machos para garantir a fecundação de todos os óvulos. Em todas as situações acima, as fêmeas se beneficiam em copular com muitos machos, ao contrário do previsto pelo paradigma Darwin-Bateman.

Muito se avançou no conhecimento sobre a poliandria, mas ainda falta muito a descobrir. Nesse cenário é que está inserida minha tese de doutorado. Ao longo dos últimos quatro anos, busquei responder duas questões gerais pouco exploradas na literatura de seleção sexual e para as quais há pouco consenso entre os pesquisadores: quais são as causas e as conseqüências da poliandria? Sabe-se que as experiências vividas durante a juventude podem dar pistas do que os animais vão encontrar quando adultos. Por isso, a morfologia e o comportamento dos organismos quando adultos podem ser determinados pela sua história pregressa ou pelo ambiente onde ocorreu seu desenvolvimento. Sabemos, por exemplo, que fêmeas de uma tarântula espanhola são mais propensas a canibalizar os machos durante o cortejo se elas tiverem passado fome durante o desenvolvimento ${ }^{7}$. Será que o ambiente social onde as fêmeas crescem pode influenciar também a propensão delas à poliandria quando adultas? Em outras palavras, as fêmeas já nascem predispostas a copular muito ou a poliandria pode ser determinada pelas experiências vividas por elas na juventude? Busquei responder essa questão no meu primeiro capítulo para entender uma das possíveis causas da poliandria. Meu modelo de estudo foi um grilo australiano que pode ser mantido facilmente em laboratório. Essa característica é importante, pois me permitiu criar fêmeas sob duas condições: uma na qual ouviram cantos somente de machos adultos atrativos e outra na qual ouviram uma mescla de cantos de machos atrativos e pouco atrativos enquanto cresciam. Quando chegaram à idade adulta, ofereci vários machos

\footnotetext{
7 Moya-Laraño, J., Orta-Ocaña, J.M., Barrientos, J.A., Bach, C., Wise, D.H. (2003). Intriguing compensation by adult female spiders for food limitation experienced as juveniles. Oikos, 101:539-548.
} 
às fêmeas desses dois grupos para saber se o grau de poliandria poderia ser influenciado pela história pregressa das fêmeas - mais especificamente, pela experiência sonora que estas fêmeas tiveram na juventude.

Como expliquei no início da introdução, a seleção sexual pode influenciar a evolução de características que funcionam como armamentos ou ornamentos nos machos. Quanto mais recursos os machos investem na produção de armamentos, menos recursos eles têm para investir em ornamentos. Por isso, na maioria das espécies, os machos ou são armados ou são ornamentados. Quando um macho pode brigar com seus rivais e assegurar a posse de uma ou várias fêmeas, esperamos encontrar armamentos bem desenvolvidos, pois a disputa pelas fêmeas se revolve com base em combates. Este é o caso de muitas rãs, nas quais os machos agarram as fêmeas durante o acasalamento e então o casal libera os gametas ao mesmo tempo. Machos maiores e com espinhos mais desenvolvidos em suas mãos conseguem agarrar melhor as fêmeas e impedir que outros machos os desalojem durante o acasalamento. Entretanto, mesmo que um macho seja bem sucedido em agarrar uma fêmea, nada impede que um macho malandrinho fique por perto e libere seu esperma sobre a desova do casal, gerando assim poliandria furtiva. A poliandria furtiva deve ser comum em rãs que se reproduzem em poças e lagos, pois o esperma precisa de um meio líquido para se locomover. Em rãs que depositam seus ovos dentro de tocas escavadas na terra, tanto a chance de um macho ser desalojado quanto a possibilidade de poliandria furtiva devem ser menores. Nessas rãs que se reproduzem em tocas terrestres, os armamentos devem ser menos desenvolvidos. Portanto, o ambiente de desova e o risco de poliandria furtiva devem ter importantes conseqüências para a evolução de características masculinas. Esse foi tema do meu segundo capítulo, no qual testei se machos de rãs que se reproduzem na terra devem ser menos armados do que seus primos que se reproduzem na água.

A seguir, estão os dois capítulos que compõem a minha tese, já formatados para publicação. Neles, você poderá encontrar o embasamento teórico detalhado das perguntas, todos os métodos de coleta e análise de dados, os resultados e a discussão. Tudo está escrito em inglês e repleto de jargão técnico. Se você fala inglês e está acostumado com a linguagem rebuscada da ecologia comportamental, pode seguir 
lendo o texto. Porém, se este não é o seu caso, pode continuar a leitura na conclusão do trabalho, na qual farei um resumo sobre os principais resultados de cada capítulo e discutirei brevemente suas implicações gerais. Independentemente se você pulará para as conclusões gerais ou encarará os dois artigos, espero que sua leitura seja prazerosa e que você aprenda algo novo.

\section{to be




\section{Acknowledgements}

We are deeply grateful to Heather Try for assistance in the lab work, to Danilo Muniz for helping with the statistical analyses, and to the Graduate Program in Ecology (University of São Paulo) for logistical support.

\section{Fundings}

EMS was supported by student grants from CAPES, GM was supported by research grants from São Paulo Research Foundation (FAPESP) and National Counsel of Technological and Scientific Development, and MMK was supported by the Australian Research Council Future Fellowship.

\section{References}

1. Bateman AJ. 1948 Intra-sexual selection in Drosophila. Heredity 2, 346-368.

2. Dewsbury DA. 2005 The Darwin-Bateman paradigm in historical context. Integr. Comp. Biol. 45, 831-7. (doi:10.1093/icb/45.5.831)

3. Taylor ML, Price TAR, Wedell N. 2014 Polyandry in nature: a global analysis. Trends Ecol. Evol. 29, 376-383. (doi:10.1016/j.tree.2014.04.005)

4. Arnqvist G, Nilsson T. 2000 The evolution of polyandry: multiple mating and female fitness in insects. Anim. Behav. 6o, 145-164. (doi:10.1006/anbe.2000.1446)

5. Slatyer RA, Mautz BS, Backwell PRY, Jennions MD. 2012 Estimating genetic benefits of polyandry from experimental studies: a meta-analysis. Biol. Rev. 87, 133. (doi:10.1111/j.1469-185X.2011.00182.x)

6. Cornwallis CK, Uller T. 2010 Towards an evolutionary ecology of sexual traits. Trends Ecol. Evol. 25, 145-52. (doi:10.1016/j.tree.2009.09.0o8)

7. Torres-Vila LM, Gragera J, Rodríguez-Molina MC, Stockel J. 2002 Heritable variation for female remating in Lobesia botrana, a usually monandrous moth. Anim. Behav. 64, 899-907. (doi:10.1006/anbe.2002.2000) 
8. Torres-Vila LM, Rodríguez-Molina MC, Gragera J, Bielza-Lino P. 2001 Polyandry in Lepidoptera: a heritable trait in Spodoptera exigua Hübner. Heredity 86, 177-183. (doi:10.1046/j.1365-2540.2001.00821.x)

9. Solymar BD, Cade WH. 1990 Heritable variation for female mating frequency in field crickets, Gryllus integer. Behav. Ecol. Sociobiol. 26, 73-76.

10. Rebar D, Zuk M, Bailey NW. 2011 Mating experience in field crickets modifies preand postcopulatory female choice in parallel. Behav. Ecol. 22, 303-309. (doi:10.1093/beheco/arq195)

11. Verzijden MN, Scobell SK, Svensson EI. 2014 The effects of experience on the development of sexual behaviour of males and females of the banded demoiselle (Calopteryx splendens). Behav. Proc. 109, 180-189. (doi:10.1016/j.beproc.2014.08.023)

12. Williams JR, Catania KC, Carter CS. 1992 Development of partner preferences in female prairie voles (Microtus ochrogaster): the role of social and sexual experience. Horm. Behav. 26, 339-349. (doi:10.1016/oo18-506X(92)90004-F)

13. Bailey NW, Zuk M. 2009 Field crickets change mating preferences using remembered social information. Biol. Lett. 5, 449-451. (doi:10.1098/rsbl.2009.0112)

14. Bailey NW, Zuk M. 2008 Acoustic experience shapes female mate choice in field crickets. Proc. R. Soc. B. 275, 2645-2650. (doi:10.1098/rspb.2008.0859)

15. Hebets EA, Vink CJ, Zealand N. 2007 Experience leads to preference : experienced females prefer brush-legged males in a population of syntopic wolf spiders. Behav. Ecol. 18, 1010-1020. (doi:10.1093/beheco/armo70)

16. Kasumovic MM, Hall MD, Brooks RC. 2012 The juvenile social environment introduces variation in the choice and expression of sexually selected traits. Ecol. Evol. 2, 1036-1047. (doi:10.1002/ece3.230)

17. Kasumovic MM, Hall MD, Try H, Brooks RC. 2011 The importance of listening: juvenile allocation shifts in response to acoustic cues of the social environment. $J$. Evol. Biol. 24, 1325-1334. (doi:10.1111/j.1420-9101.2011.02267.x)

18. Cunningham EJA, Russell AF. 2000 Egg investment is influenced by male attractiveness in the mallard. Nature 404, 74-77. (doi:10.1038/35003565)

19. Evans AR. 1988 Mating systems and reproductive strategies in three Australian gryllid crickets: Bobilla victoriae Otte, Balamara gidya Otte and Teleogryllus 
commodus Walker (Orthoptera: Gryllidae: Nemobiinae; Trigonidiinae; Gryllinae). Ethology 78, 21-52.

20. Jennions MD, Drayton JM, Brooks R, Hunt J. 2007 Do female black field crickets Teleogryllus commodus benefit from polyandry? J. Evol. Biol. 2o, 1469-1477. (doi:10.1111/j.1420-9101.2007.01333.x)

21. Hunt J, Brooks R, Jennions MDD. 2005 Female mate choice as a conditiondependent life-history trait. Am. Nat. 166, 79-92. (doi:10.1086/430672)

22. Hall MD, Bussière LF, Hunt J, Brooks R. 2008 Experimental evidence that sexual conflict influences the opportunity, form and intensity of sexual selection. Evolution 62, 2305-2315. (doi:10.1111/j.1558-5646.2008.00436.x)

23. Simmons LW, Thomas ML, Simmons FW, Zuk M. 2013 Behavioral female preferences for acoustic and olfactory signals during courtship: male crickets send multiple messages. Behav. Ecol. 24, 1099-1107. (doi:10.1093/beheco/arto36)

24. Bentsen CL, Hunt J, Jennions MD, Brooks R. 2006 Complex multivariate sexual selection on male acoustic signaling in a wild population of Teleogryllus commodus. Am. Nat. 167, E102-E116. (doi:10.1086/501376)

25. Hunt J, Brooks R, Jennions MD, Smith MJ, Bentsen CL, Bussière LF. 2004 Highquality male field crickets invest heavily in sexual display but die young. Nature 432, 1024-1027. (doi:10.1038/natureo3084)

26. Kasumovic MM, Chen Z, Wilkins MR. 2016 Australian black field crickets show changes in neural gene expression associated with socially-induced morphological, life-history, and behavioral plasticity. BMC Genomics 17, 1-16. (doi:10.1186/s12864o16-3119-y)

27. Edward DA. 2015 The description of mate choice. Behav. Ecol. 26, 301-310. (doi:10.1093/beheco/aru142)

28. Bussière LF, Hunt J, Jennions MD, Brooks R. 2006 Sexual conflict and cryptic female choice in the black field cricket, Teleogryllus commodus. Evolution 6o, 7928oo. (doi:10.1111/j.0014-3820.2006.tbo1157.x)

29. Loher W, Rence B. 1978 The mating behavior of Teleogryllus commodus (Walker) and its central and peripheral control. Z. Tierpsychol. 46, 225-259. (doi:10.111//j.1439-0310.1978.tbo1447.x) 
30. Barton K. 2009 MuMIn: Multi-Model Inference. R package version 0.12.2/r18. Available at: http://R-Forge.R-project.org/projects/mumin/.

31. Burnham KP, Anderson DR. 2002 Model Selection and Multimodel Inference: A Practical Information-Theoretic Approach. 2nd ed. New York, Springer. (doi:10.1016/j.ecolmodel.2003.11.004)

32. Schielzeth H. 2010 Simple means to improve the interpretability of regression coefficients. Methods Ecol. Evol. 1, 103-113. (doi:10.1111/j.2041-210X.2010.00012.X)

33. Fox CW. 1993 Multiple mating, lifetime fecundity and female mortality of the bruchid beetle, Callosobruchus maculatus (Coleoptera: Bruchidae). Funct. Ecol. 7, 203-208. (doi:10.2307/2389888)

34. Gonzáles A, Rossini C, Eisner M, Eisner T. 1999 Sexually transmitted chemical defense in a moth (Utetheisa ornatrix). Proc. Natl. Acad. Sci. USA 96, 5570-5574. (doi:10.1073/pnas.96.10.5570)

35. Clutton-Brock TH, Parker GA. 1995. Sexual coercion in animal societies. Anim. Behav. 49, 1345-1365. (doi: 10.1006/anbe.1995.0166)

36. Shuster SM, Wade MJ. 2003 Mating Systems and Strategies. Princeton, Princeton University Press.

37. Gerhardt HC, Huber F. 2002. Acoustic Communication in Insects and Anurans: Common Problems and Diverse Solutions. Chicago, University of Chicago Press.

38. Loher W, Ganjian I, Kubo I, Stanley-Samuelson D, Tobe SS. 1981 Prostaglandins: their role in egg-laying of the cricket Teleogryllus commodus. Proc. Natl. Acad. Sci. USA 78, 7835-7838. (doi:10.1073/pnas.78.12.7835)

39. Eberhard WG. 1996 Female Control: Sexual Selection by Cryptic Female Choice. Princeton, Princeton University Press.

40. Drayton JM, Boeke JEK, Jennions MD. 2013 Immune challenge and pre- and postcopulatory female choice in the cricket Teleogryllus commodus. J. Insect Behav. 26, 176-190. (doi:10.1007/s10905-012-9347-3)

41. Simmons LW. 2001. Sperm Competition and Its Evolutionary Consequences in the Insects. Princeton, Princeton University Press.

42. Shuster SM, Briggs WR, Dennis PA. 2013. How multiple mating by females affects sexual selection. Phil. Trans. R. Soc. B 368, 20120046. (doi: 10.1098/rstb.2012.0046). 
about sexual selection acting on frogs, as well as other external fertilizer species, future studies should explore pre- and post-mating selective pressures acting on the little known tropical species.

\section{Acknowledgements}

We are grateful to Bruno A. Buzatto for assistance in the comparative analyses and comments on the manuscript, to Ariovaldo A. Giaretta, Rebecca Hale, Danilo G. Muniz, Taran Grant, and Eduardo S. A. Santos for comments on early versions of the manuscript, to Cynthia P. A. Prado for helping with sex determination in some species and for providing unpublished information on the natural history of some species included in our dataset, to the curators of the museums, Célio F. B. Haddad and Hussam El Dine Zaher, for allowing us to have access to specimens of the collections, to Florestas Pampeanas and Biofaces, Raúl Maneyro, and Felipe Villegas for allowing us to use the photographs shown in Figure 1, and to the Graduate Program in Ecology (University of São Paulo) for logistical support. EMS was supported by a student grant from CAPES and GM was supported by research grants from São Paulo Research Foundation (FAPESP 2015/10448-4) and National Counsel of Technological and Scientific Development (CNPq 306550/2014-8).

\section{References}

Alonzo, S. H., \& Warner, R. R. (2000). Allocation to mate guarding or increased sperm production in a Mediterranean wrasse. The American Naturalist, 156(3), 266-275. doi.org/10.1086/303391

Brockmann, H. J., Nguyen, C. N., \& Potts, W. (2000). Paternity in horseshoe crabs when spawning in multiple-male groups. Animal Behaviour, 6o(6), 837-849. doi.org/10.1006/anbe.2000.1547

Buzatto, B. A., Roberts, J. D., \& Simmons, L. W. (2015). Sperm competition and the evolution of precopulatory weapons: Increasing male density promotes sperm competition and reduces selection on arm strength in a chorusing frog. Evolution, 69(10), 2613-2624. doi.org/10.1111/evo.12766 
Buzatto, B. A., Tomkins, J. L., Simmons, L. W., \& Machado, G. (2014). Correlated evolution of sexual dimorphism and male dimorphism in a clade of neotropical harvestmen. Evolution, 68(6), 1671-1686. doi.org/10.1111/evo.12395

Chargé, R., Teplitsky, C., Hingrat, Y., Saint Jalme, M., Lacroix, F., \& Sorci, G. (2013). Quantitative genetics of sexual display, ejaculate quality and size in a lekking species. Journal of Animal Ecology, 82(2), 399-407. doi.org/10.1111/1365-2656.12023

Clark, D. L., \& Peters, S. E. (2006). Isometric contractile properties of sexually dimorphic forelimb muscles in the marine toad Bufo marinus Linnaeus 1758: functional analysis and implications for amplexus. The Journal of Experimental Biology, 209, 3448-3456. doi.org/10.1242/jeb.02396

Duellman, W. E., \& Trueb, L. (1986). Biology of Amphibians. McGrawHill Inc New York. Baltimore, Maryland: The Johns Hopkins University Press.

Eberhard, W. G. (1996). Female Control: Sexual Selection by Cryptic Female Choice. Cambridge, Massachussetts: Harvard University Press.

Eberhard, W. G. (2009). Postcopulatory sexual selection: Darwin's omission and its consequences. Proceedings of the National Academy of Sciences of the United States of America, 106(1), 10025-10032.

Fairbairn, D. J., Blanckenhorn, W. U., \& Székely, T. (2007). Sex, Size and Gender Roles Evolutionary Studies of Sexual Size Dimorphism. New York: Oxford University Press.

Ferrandiz-Rovira, M., Lemaître, J. F., Lardy, S., López, B. C., \& Cohas, A. (2014). Do preand post-copulatory sexually selected traits covary in large herbivores? BMC Evolutionary Biology, 14(1), 14-79. doi.org/10.1186/1471-2148-14-79

Fitzpatrick, J. L., Almbro, M., Gonzalez-Voyer, A., Kolm, N., \& Simmons, L. W. (2012). Male Contest Competition And The Coevolution Of Weaponry And Testes In Pinnipeds. Evolution, 66(11), 3595-3604. doi.org/10.1111/j.1558-5646.2012.01713.X

Forester, D. C., \& Thompson, K. J. (1998). Gauntlet behaviour as a male sexual tactic in the American toad (Amphibia: Bufonidae). Behaviour, 135(2), 99-119. doi.org/10.1163/156853998793066375

Fouquet, A., Blotto, B. L., Maronna, M. M., Verdade, V. K., Juncá, F. A., De Sá, R., \& Rodrigues, M. T. (2013). Unexpected phylogenetic positions of the genera Rupirana and Crossodactylodes reveal insights into the biogeography and reproductive 
evolution of leptodactylid frogs. Molecular Phylogenetics and Evolution, 67(2), 445457. doi.org/10.1016/j.ympev.2013.02.009

Frost, D. R. (2016). Amphibian Species of the World: An Online Reference. Version 5.6 Retrieved from http://research.amnh.org/herpetology/amphibia/index.html.

Galvis, A. R. A., \& de Sá, R. O. (2018). Leptodactylus validus Garman, 1888 in Colombia: its distribution and identification. ZooKeys, 737(February), 113-123. doi.org/10.3897/zookeys.737.20442

Giaretta, A. A., \& Kokubum, M. N. de C. (2004). Reproductive ecology of Leptodactylus furnarius Sazima \& Bokermann, 1978, a frog that lays eggs in underground chambers. Herpetozoa, 16(3/4), 115-126.

Gibson, R. C., \& Buley, K. R. (2004). Maternal Care and Obligatory Oophagy in Leptodactylus fallax: A New Reproductive Mode in Frogs. Copeia, 2004(1), 128-135. doi.org/10.1643/CE-02-091R2

Gomez-Mestre, I., Pyron, R. A., \& Wiens, J. J. (2012). Phylogenetic analyses reveal unexpected patterns in the evolution of reproductive modes in frog. Evolution, 66(12), 3687-3700. doi.org/10.1111/j.1558-5646.2012.01715.X

Haddad, C. F. B., \& Prado, C. P. A. (2005). Reproductive modes in frogs and their unexpected diversity in the Atlantic Forest of Brazil. BioScience, 55(3), 207-217. doi.org/10.1641/ooo6-3568(2005)055[0207:RMIFAT]2.0.CO;2

Han, X., \& Fu, J. (2013). Does life history shape sexual size dimorphism in anurans? A comparative analysis. BMC Evolutionary Biology, 13(1), 27. doi.org/10.1186/1471-2148$13-27$

Hecnar, S. J., \& M'Closkey, R. T. (1997). The effects of predatory fish on amphibian species richness and distribution. Biological Conservation, 79(2-3), 123-131. doi.org/10.1016/Sooo6-3207(96)oo113-9

Heyer, W. R. (1969). The adaptive ecology of the species groups of the Genus Leptodactylus (Amphibia, Leptodactylidae). Evolution, 23(3), 421-428.

Heyer, W. R. W. (1978). Systematics of the fuscus group of the frog genus Leptodactylus (Amphibia, Leptodactylidae). Smithsonian Contributions to Zoology, $29,1-85$. 
Higginson, D. M., Miller, K. B., Segraves, K. A., \& Pitnick, S. (2012). Convergence, recurrence and diversification of complex sperm traits in diving beetles (Dytiscidae). Evolution, 66(5), 1650-1661. doi.org/10.1111/j.1558-5646.2011.01532.X

Hutchings, J. A., \& Myers, R. A. (1987). Escalation of an asymmetric contest: mortality resulting from mate competition in Atlantic salmon, Salmo salar. Canadian Journal of Zoology, 65(February 2011), 766-768. doi.org/10.1139/z87-120

Jennions, M. D., \& Passmore, N. I. (1993). Sperm competition in frogs: testis size and a “sterile male" experiment on Chiromantis xerampelina (Rhacophoridae). Biological Journal of the Linnean Society, 50(3), 211-220. doi.org/10.1111/j.10958312.1993.tboog27.x

Jones, A. G., \& Ratterman, N. L. (2009). Mate choice and sexual selection: what have we learned since Darwin? Proceedings of the National Academy of Sciences of the United States of America, 106 Suppl, 10001-10008. doi.org/10.1073/pnas.0901129106

Joseph, P. N., Emberts, Z., Sasson, D. A., \& Miller, C. W. (2017). Males that drop a sexually selected weapon grow larger testes. Evolution, 72(1), 113-122. doi.org/10.1111/evo.13387

Kupfer, A. (2007). Sexual size dimorphism in amphibians: an overview. In D. Fairbairn, W. U. Blanckenhorn, \& T. Székely (Eds.), Sex, Size, and Gender Roles - Evolutionary Studies of Sexual Size Dimorphism (pp. 50-63). Oxford, UK: Oxford University Press.

Kvarnemo, C., \& Simmons, L. W. (2013). Polyandry as a mediator of sexual selection before and after mating. Philosophical Transactions of the Royal Society of London. Series B, Biological Sciences, 368(1613), 20120042. doi.org/10.1098/rstb.2012.0042

Lamar, W. W., \& Wild, E. R. (1995). Comments on the natural history of Lithodytes lineatus (Anura: Leptodactylidae), with a description of the tadpole. Herpetological Natural History, 3(2), 135-142.

Levitan, D. R. (2004). Density-dependent sexual selection in external fertilizers: variances in male and female fertilization success along the continuum from sperm limitation to sexual conflict in the sea urchin Strongylocentrotus franciscanus. The American Naturalist, 164(3), 298-309. doi.org/10.1086/423150

Luo, Z., Li, C., Wang, H., Shen, H., Zhao, M., Gu, Q., Wu, H. (2016). Male-male competition drives sexual selection and group spawning in the Omei treefrog, 
Rhacophorus omeimontis. Behavioral Ecology and Sociobiology, 70(4), 593-605. doi.org/10.1007/s00265-016-2078-2

Lüpold, S., Jin, L., \& Liao, W. B. (2017). Population density and structure drive differential investment in pre- and postmating sexual traits in frogs. Evolution, $71(6)$, 1686-1699. doi.org/10.1111/evo.13246

Lüpold, S., Tomkins, J. L., Simmons, L. W., \& Fitzpatrick, J. L. (2014). Female monopolization mediates the relationship between pre- and postcopulatory sexual traits. Nature Communcations, 5, 3184. doi.org/10.1038/ncomms4184

Macías-Ordóñez, R., Macedo, R. H., \& Machado, G. (2013). Macroecology of sexual selection: large-scale influence of climate on sexually selected traits. In R. H. Macedo \& G. Machado (Eds.), Sexual Selection: Perspectives and Models from the Neotropics (pp. 1-32). Amsterdam: Elsevier.

Maddison, W. P., \& Maddison, D. R. (2011). Mesquite: modular system for evolutionary analysis. Retrieved from http://mesquiteproject.org

Malo, A. F., Roldan, E. R. S., Garde, J., Soler, A. J., \& Gomendio, M. (2005). Antlers honestly advertise sperm production and quality. Proceedings of the Royal Society B: Biological Sciences, 272(1559), 149-157. doi.org/10.1098/rspb.2004.2933

Martins, M. (1988). Biologia reprodutiva de Leptodactylus fuscus em Boa Vista, Roraima (Amphibia: Anura). Revista Brasileira de Biologia, 48(4), 969-977.

Nali, R. C., \& Prado, C. P. A. (2014). Complex call with different messages in Bokermannohyla ibitiguara (Anura, Hylidae), a gladiator frog of the Brazilian Cerrado. Journal of Herpetology, 48(3), 407-414.

Pagel, M. (1994). Detecting correlated evolution on phylogenies : a general method for the comparative analysis of discrete characters. Proceedings of the Royal Society Biological Sciences, 255. doi.org/10.1098/rspb.1994.00o6

Pagel, M., \& Meade, A. (2006). Bayesian analysis of correlated evolution of discrete characters by reversible-jump Markov chain Monte Carlo. The American Naturalist, $167(6), 808-825$.

Parker, G. A., Lessells, C. M., \& Simmons, L. W. (2012). Sperm competition games: a general model for precopulatory male-male competition. Evolution, 67(1), 95-109. doi.org/10.5061/dryad.d71n2 
Parker, G. A., \& Pizzari, T. (2015). Sexual selection: the logical imperative. In T. Hoquet (Ed.), Current Perspectives on Sexual Selection - What's left after Darwin? (Vol. 9, pp. 119-163). New York, New York: Springer. doi.org/10.1007/978-94-017-9585-2

Pereira, E. B., Collevatti, R. G., Kokubum, M. N. de C., Miranda, N. E. de O., \& Maciel, N. M. (2015). Ancestral reconstruction of reproductive traits shows no tendency toward terrestriality in leptodactyline frogs. BMC Evolutionary Biology, 15(1), 91. doi.org/10.1186/s12862-015-0365-6

Prado, C. P. A., Uetanabaro, M., \& Haddad, C. F. B. (2002). Description of a new reproductive mode in Leptodactylus (Anura, Leptodactylidae), with a review of the reproductive specialization toward terrestriality in the genus. Copeia, 4(4), 1128-1133. doi.org/10.1643/0045-8511(2002)002[1128:DOANRM]2.o.CO;2

Prado, C. P. de A. P., \& Haddad, C. F. B. (2003). Testes size in Leptodactylid frogs and occurrence of multimale spawning in the genus Leptodactylus in Brazil. Journal of Herpetology, 37(2), 354-362.

Pyron, R. A., \& Wiens, J. J. (2011). A large-scale phylogeny of Amphibia including over 2800 species, and a revised classification of extant frogs, salamanders, and caecilians. Molecular Phylogenetics and Evolution, 61(2), 543-583. doi.org/10.1016/j.ympev.2011.06.012

Reznick, D., Nunney, L., \& Tessier, A. (2000). Big houses, big cars, superfleas and the costs of reproduction. Trends in Ecology and Evolution, 15(10), 421-425. doi.org/10.1038/316020ao

Roberts, J. D., \& Byrne, P. G. (2011). Polyandry, sperm competition, and the evolution of Anuran Amphibians. Advances in the Study of Behavior, 43, 1-53. doi.org/10.1016/B978-0-12-380896-7.00001-0

Rogers, D. W., Denniff, M., Chapman, T., Fowler, K., \& Pomiankowski, A. (20o8). Male sexual ornament size is positively associated with reproductive morphology and enhanced fertility in the stalk-eyed fly Teleopsis dalmanni. BMC Evolutionary Biology, 8(1), 236. doi.org/10.1186/1471-2148-8-236

Sá, R. O. De, Grant, T., Camargo, A., Heyer, W. R., Ponssa, M. L., \& Stanley, E. (2014). Systematics of the Neotropical genus Leptodactylus Fitzinger, 1826 (Anura: Leptodactylidae): phylogeny, the relevance of non-molecular evidence, and species 
accounts. South American Journal of Herpetology, 9(s1), S1-S1oo. doi.org/10.2994/SAJH-D-13-00022.1

Santos-Silva, C. R., Santos, E. D. S., \& Ferrari, S. F. (2012). Multiple amplexus on Phyllomedusa bahiana (Hylidae : Phyllomedusinae) in the Caatinga Northeast Brazil, Herpetology Notes, 5, 171-172.

Shine, R. (1979). Sexual selection and sexual dimorphism in the Amphibia. Copeia, 1979(2), 297-306.

Silva, W. R. da, \& Giaretta, A. A. (2009). On the natural history of Leptodactylus syphax with comments on the evolution of reproductive features in the L. pentadactylus species group (Anura, Leptodactylidae). Journal of Natural History, 43(3-4), 191-203. doi.org/10.1080/00222930802484618

Silva, W. R., Giaretta, A. A., Facure, K. G., da Silva, W. R., Giaretta, A. A., \& Facure, K. G. (2005). On the natural history of the South American pepper frog, Leptodactylus labyrinthicus (Spix, 1824) (Anura: Leptodactylidae). Journal of Natural History, 39(7), 555-566. doi.org/10.1080/00222930410001671273

Simmons, L. W., \& Emlen, D. J. (2006). Evolutionary trade-off between weapons and testes. Proceedings of the National Academy of Sciences, 103(44), 16346-16351. doi.org/10.1073/pnas.0603474103

Simmons, L. W., Lüpold, S., \& Fitzpatrick, J. L. (2017). Evolutionary trade-off between secondary sexual traits and ejaculates. Trends in Ecology and Evolution, 32(12), 964976. doi.org/10.1016/j.tree.2017.09.011

Simmons, L. W., Roberts, J. D., \& Dziminski, M. A. (2009). Egg jelly influences sperm motility in the externally fertilizing frog, Crinia georgiana. Journal of Evolutionary Biology, 22(1), 225-229. doi.org/10.1111/j.1420-9101.2008.01628.x

Stoltz, J. A., \& Neff, B. D. (2006). Male size and mating tactic influence proximity to females during sperm competition in bluegill sunfish. Behavioral Ecology and Sociobiology, 59(6), 811-818. doi.org/10.1007/soo265-005-0127-3

Tsuji, H. (2004). Reproductive ecology and mating success of male Limnonectes kuhlii, a fanged frog from Taiwan. Herpetologica, 6o(2), 155-167. 
Tuni, C., Weber, S., Bilde, T., \& Uhl, G. (2017). Male spiders reduce pre- and postmating sexual investment in response to sperm competition risk. Behavioral Ecology, 28(4), 1030-1036. doi.org/10.1093/beheco/arxo61

Vieites, D. R., Nieto-Román, S., Barluenga, M., Palanca, A., Vences, M., \& Meyer, A. (2004). Post-mating clutch piracy in an amphibian. Nature, 431(7006), 305-308. doi.org/10.1038/natureo2879

Wells, K. D. D. (2007). The Ecology and Behavior of Amphibians. Animal Behaviour (Vol. 25). Chicago, Illinois: The University of Chicago Press. doi.org/10.1007/s13398$014-0173-7.2$

Zamudio, K. R., Bell, R. C., Nali, R. C., Haddad, C. F. B., \& Prado, C. P. A. (2016). Polyandry, Predation, and the Evolution of Frog Reproductive Modes. The American Naturalist, 188(september), Sooo-Sooo. doi.org/10.1086/687547

Zamudio, K. R., \& Chan, L. M. (2008). Alternative reproductive tactics in amphibians. In R. F. Oliveira, M. Taborsky, \& H. J. Brockmann (Eds.), Alternative Reproductive Tactics (Vol. 30, pp. 300-331). Cambridge, UK: Cambridge University Press. 


\section{References of papers cited in Table S1}

Aichinger, M. 1987. Annual activity patterns of anurans in a seasonal neotropical environment. Oecologia 71:583-592.

Almeida, A. de P., and A. Angulo. 2006. A new species of Leptodactylus (Anura: Leptodactylidae) from the state of Espírito Santo, Brazil, with remarks on the systematics of associated populations. Zootaxa 1334:1-25.

Almeida, A. de P., and A. Angulo. 2002. Adenomera aff. marmorata (NCN). Reproduction. Herpetol. Rev. 33:197-198.

Andersson, L. G. 1945. Batrachians from East Ecuador. Ark. Zool. 37:1-88.

Arzabe, C., and C. P. A. Prado. 2006. Distinct architectures of subterranean nests in the genus Leptodactylus of the fuscus group (Anura, Leptodactylidae). Herpetol. Rev. 37:23-26.

Ávila-Pires, T. C. S., M. S. Hoogmoed, and W. A. Da Rocha. 2010. Notes on the vertebrates of northern Pará, Brazil: a forgotten part of the Guianan Region, I. Herpetofauna. Bol. Mus. Para. Emilio Goeldi. Ciências Nat. 5:13-112.

Bitar, Y. O. C., L. P. C. Pinheiro, P. S. Abe, and M. C. Santos-Costa. 2012. Species composition and reproductive modes of anurans from a transitional Amazonian forest, Brazil. Zoologia 29:19-26.

Boistel, R., J. De Massary, and A. Angulo. 2006. Description of a new species of the genus Adenomera (Amphibia , Anura, Leptodactylidae) from French Guiana. Acta Herpetol. 1:1-14.

Brandão, R. A., G. F. R. Álvares, and R. O. de Sá. 2013. The advertisement call of the poorly known Leptodactylus tapiti (Anura, Leptodactylidae). Zootaxa 3616:284-286.

Brandão, R. A., and W. R. Heyer. 2005. The complex calls of Leptodactylus pustulatus. Amphibia-Reptilia 26:566-570.

Caramaschi, U., R. N. Feio, and V.A. São-Pedro. 2008. A new species of Leptodactylus Fitzinger (Anura, Leptodactylidae) from Serra do Brigadeiro, State of Minas Gerais, Southeastern Brazil. Zootaxa 1861:44-54.

Carvalho, T. R. D. E., and A. A. Giaretta. 2013. Taxonomic circumscription of Adenomera martinezi (Bokermann, 1956) (Anura: Leptodactylidae: Leptodactylinae) 
with the recognition of a new cryptic taxon through a bioacoustic approach. Zootaxa 3701:207-237.

Carvalho, T. R. de, F. S. F. Leite, and T. L. Pezzuti. 2013. A new species of Leptodactylus Fitzinger (Anura, Leptodactylidae, Leptodactylinae) from montane rock fields of the Chapada Diamantina, northeastern Brazil. Zootaxa 3701:349-364.

Cassini, C. S., V. G. D. Orrico, I. R. Dias, M. Solé, and C. F. B. Haddad. 2013. Phenotypic variation of Leptodactylus cupreus Caramaschi, São-Pedro and Feio, 2008 (Anura, Leptodactylidae). Zootaxa 3616:73-84.

Cei, J. M. 1980. Amphibians of Argentina. Monitore z. Universita degli studi di Firenze, Firenze, Italy.

de la Riva, I. J. 1995. A new reproductive mode for the genus Adenomera (Amphibia, Anura: Leptodactylidae): taxonomic implications for certain Bolivian and Paraguyan populations. Stud. Neotrop. Fauna Environ. 30:15-29.

de la Riva, I., J. Köhler, S. Lötters, and S. Reichle. 2000. Ten years of research on Bolivian amphibians: updated checklist, distribution, taxonomic problems, literature and iconography. Rev. Española Herpetol. 14:19-164.

Deiques, C. H., L. F. Stahnke, M. Reinke, and P. Schmitt. 2007. Anfíbios e répteis do Parque Nacional de Aparados da Serra Rio Grande do Sul, Santa Catarina, Brasil: guia ilustrado. Manuais da USEB, Pelotas, Brazil.

Dent, J. N. 1956. Observations on the life history and development of Leptodactylus albilabris. Am. Soc. Ichthyol. Herpetol. 4:207-210.

Dixon, J. R., and W. H. Heyer. 1968. Anuran succession in a temporary pond in Colima, Mexico. Bull. South. Calif. Acad. Sci. 67:129-142.

Dixon, J. R., and M. A. Staton. 1976. Some aspects of the biology of Leptodactylus macrosternum Miranda-Ribeiro (Anura: Leptodactylidae) of the Venezuelan Llanos. Herpetologica 32:227-232.

Downie, J. R. 1996. A new example of female parental behaviour in Leptodactylus validus a frog the leptodactylid "melanonotus" species group. Herpetol. J. 6:32-34.

Duellman, W. E. 1997. Amphibians of La Escalera Region, Southeastern Venezuela: tamonomy, ecology and biogeography. Sci. Pap. Nat. Hist. Mus. Univ. Kansas 3:152. 
Emerson, S. B. 1976. Burrowing in frogs. J. Morphol. 149:437-458.

EOL, Encyclopedia of Life. 2014. Avilable at www.eol.org. Accessed in December 15, 2017.

Giaretta, A. A., and M. N. de C. Kokubum. 2004. Reproductive ecology of Leptodactylus furnarius Sazima \& Bokermann, 1978, a frog that lays eggs in underground chambers. Herpetozoa 16:115-126.

Gibson, R. C., and K. R. Buley. 2004. Maternal care and obligatory oophagy in Leptodactylus fallax: a new reproductive mode in frogs. Copeia 2004:128-135.

Guarino, F.M., G. Garcia, and F. Andreone. 2014. Huge but moderately long-lived: age structure of Leptodactylus fallax, from Montserrat, West Indies. Herpetol. J. 24:167-173.

Haddad, C. F. B., and C. P. A. Prado. 2005. Reproductive modes in frogs and their unexpected diversity in the Atlantic Forest of Brazil. Bioscience 55:207-217.

Hero, J.-M., and U. Galatti. 1990. Characteristics distinguishing Leptodactylus pentadactylus and L. knudseni in the Central Amazon Rainforest. J. Herpetol. $24: 226-228$.

Heyer, M. M., W. R. Heyer, and R. O. de Sá. 2006. Leptodactylus fragilis (Brocchi): white-lipped thin-toed frog. Cat. Am. Amphib. Reptil. 830:1-2.

Heyer, W. H. 1973. Systematics of the marmoratus group of the frog genus Leptodactylus (Amphibia, Leptodcatylidae). Contrib. Sci. Los Angeles Cty. Mus. Nat. Hist. 251:1-27.

Heyer, W. H. 1998. The relationships of Leptodactylus diedrus (Anura, Leptodactylidae). Alytes 16:1-24.

Heyer, W. H. 2005. Variation and taxonomic clarification of the large species of the Leptodactylus pentadactylus species group (Amphibia: Leptodactylidae) from Middle America, Northern South America, and Amazonia. Arq. Zool. 37:269-348.

Heyer, W. H., A. S. Rand, C. A. G. da Cruz, O. L. Peixoto, and C. E. Nelson. 1990. Frogs of Boraceia. Arq. Zool. 31:231-410. São Paulo, Brazil.

Heyer, W. R. 1974. Relationships of the marmoratus species group (Amphibia, Leptodactylidae) within the subfamily Leptodactylinae. Contrib. Sci. Los Angeles Cty. Mus. Nat. Hist. 253:1-48. 
Heyer, W. R. 1995. South American rocky habitat Leptodactylus (Amphibia: Anura: Leptodactylidae) with description of two new species. Proc. Biol. Soc. Washington 108:695-716.

Heyer, W. R. 1970. Studies on the frogs of the genus Leptodactylus (Amphibia: Leptodactylidae). VI. Biosystematics of the melanonotus group. Contrib. Sci. Los Angeles Cty. Mus. Nat. Hist. 191:1-48.

Heyer, W. R. 1969. The adaptive ecology of the species groups of the genus Leptodactylus (Amphibia, Leptodactylidae). Evolution 23:421-428.

Heyer, W. R. 1994. Variation within the Leptodactylus podicipinus-wagneri complex of frogs (Amphibia: Leptodactylidae). Smithson. Contrib. Zool. 546:1-124.

Heyer, W. R., and C. L. Barrio-Amorós. 2009. The advertisement calls of two sympatric frogs Leptodactylus lithonaetes (Amphibia: Anura: Leptodactylidae) and Pristimantis vilarsi (Amphibia: Anura: Strabomantidae). Proc. Biol. Soc. Washington 122:282-291.

Heyer, W. R., and R. O. De Sá. 2011. Variation, systematics, and relationships of the Leptodactylus bolivianus complex (Amphibia: Anura: Leptodactylidae). Smithson. Contrib. Zool. 635:1-58.

Heyer, W. R., R. O. de Sá, J. R. McCraine, and L. D. Wilson. 1996. Leptodactylus silvanimbus (Amphibia: Anura: Leptodactylidae): natural history notes, advertisement call, and relationships. Herpetol. Nat. Hist. 4:169-174.

Heyer, W. R., R. O. de Sá, and S. Muller. 2005. On the enigmatic distribution of the Honduran endemic Leptodactylus silvanimbus (Amphibia: Anura: Leptodactylidae). Pp. 81-101 in M. A. Donnely, B. I. Crother, C. Guyer, M. H. Wake, and M. E. White, eds. Ecology and Evolution in the Tropics, A Herpetological Perspective. University of Chicago Press, London, UK.

Heyer, W. R., and M. M. Heyer. 2004. Leptodactylus furnarius Sazima and Bokermann (Cerrado Oven Frog). Cat. Am. Amphib. Reptil. 785:3-5.

Heyer, W. R., and M. M. Heyer. 2012. Systematics, distribution, and bibliography of the frog Leptodactylus validus Garman, 1888 (Amphibia: Leptodactylidae). Proc. Biol. Soc. Washington 125:276-294. 
Heyer, W. R., M. M. Heyer, and R. O. de Sá. 2010. Leptodactylus syphax Bokermann Burgundy thin toed frog. Cat. Am. Amphib. Reptil. 868:1-9.

Heyer, W. R., and F. A. Juncá. 2003. Leptodactylus caatingae, a new species of frog from eastern Brazil (Amphibia: Anura: Leptodactylidae). Proc. Biol. Soc. Washinton 116:317-329.

Heyer, W. R., A. S. Rand, C. A. G. da Cruz, and O. L. Peixoto. 1988. Decimations, extinctions, and colonizations of frog populations in Southeast Brazil and their evolutionary implications. Biotropica 20:230-235.

Heyer, W. R. W. 1978. Systematics of the fuscus group of the frog genus Leptodactylus (Amphibia, Leptodactylidae). Smithson. Contrib. Zool. 29:1-85.

Hoffmann, H. 2006. Observations on behaviour and parental care of Leptodactylus melanonotus (Hallowell) in Costa Rica. Salamandra 42:109-116.

INPA, Instituto Nacional de Pesquisas da Amazônia. 2015. Available at www.portal.inpa.gov.br. Accessed in January 8, 2018.

Izecksohn, E. 1976. Uma nova especie de Leptodactylus do Estado do Rio de Janeiro, Brasil (Amphibia, Anura, Leptodactylidae). Rev. Bras. Biol. 36:527-530.

Izecksohn, E., and S. P. De Carvalho-e-Silva. 2001. Anfibios do municipio do Rio de Janeiro. Editora UFRJ, Rio de Janeiro, Brazil.

Jansen, M., L. Gonzales Álvarez, and G. Köhler. 2007. New species of Hydrolaetare (Anura, Leptodactylidae) from Bolivia with some notes on its natural history. J. Herpetol. 41:724-732.

Köhler, J. 2000. Amphibian diversity in Bolivia: a study with special reference to montane forest regions. Bonn Zool Monogr. 48:1-243.

Kok, P. J. R., M. N. C. Kokubum, R. D. Macculloch, and A. Lathrop. 2007. Morphological variation in Leptodactylus lutzi (Anura, Leptodactylidae) with description of its advertisement call and notes on its courtship behavior. Phyllomedusa 6:45-60.

Kokubum, M. N. de C. 2008. Ecologia reprodutiva e diversidade acústica de espécies de Leptodactylus do grupo marmoratus (Anura: Leptodactylidae). PhD Dissertation, Universidade de Brasília, Brazil. 
Kokubum, M. N. C. de, N. M. Maciel, R. H. Matsushita, A. T. de Queiróz-Júnior, and A. Sebben. 2009. Reproductive biology of the Brazilian sibilator frog Leptodactylus troglodytes. Herpetol. J. 19:119-126.

Kopp, K., L. Signorelli, and R. P. Bastos. 2010. Distribuição temporal e diversidade de modos reprodutivos de anfíbios anuros no Parque Nacional das Emas e entorno, Estado de Goiás, Brasil. Iheringia Série Zool. 100:192-200.

Kwet, A., and A. Angulo. 2002. A new species of Adenomera (Anura, Leptodactylidae) from the Araucaria forest of Rio Grande so Sul (Brazil), with comments in the systematic status of southern populations of the genus. Alytes 20:28-43.

Kwet, A., and M. Di-Bernardo. 1999. Anfíbios - Amphibien - Amphibians. EDIPUCRS, Porto Alegre, Brazil.

Kwet, A., J. Steiner, and A. Zillikens. 2009. A new species of Adenomera (Amphibia: Anura: Leptodactylidae) from the Atlantic rain forest in Santa Catarina, Southern Brazil. Stud. Neotrop. Fauna Environ. 44:93-107.

Lima, A. P., W. E. Magnusson, M. Menin, L. K. Erdtmann, D. J. Rodrigues, C. Keller, and W. Höld. 2006. Guide to the frogs of Reserva Adolpho Ducke, Central Amazonia. Áttema Design Editorial, Manaus, Brazil.

Lutz, A. 1926. Observações sobre Batrachios brasileiros. Parte I: O genero Leptodactylus Fitzinger. Mem. Inst. Oswaldo Cruz XIX:139-57.

Lutz, A. 1930. Second paper on brasilian and some closely related species of the genus Leptodactylus. Mem. Inst. Oswaldo Cruz XXIII:21-34.

Lutz, B. 1948. Ontogenetic evolution in frogs. Evolution 2:29-39.

Lutz, B. 1947. Trends towards non-aquatic and direct development in frogs. Copeia $1947: 242-252$.

Martins, M. 1988. Biologia reprodutiva de Leptodactylus fuscus em Boa Vista, Roraima (Amphibia: Anura). Rev. Bras. Biol. 48:969-977.

McCraine, J. R., L. D. Wilson, and L. Porras. 1980. A new species of Leptodactylus from the cloud forests of Honduras. J. Herpetol. 14:361-367. 
Menin, M., A. P. Lima, W. E. Magnusson, and F. Waldez. 2007. Topographic and edaphic effects on the distribution of terrestrially reproducing anurans in Central Amazonia: mesoscale spatial patterns. J. Trop. Ecol. 23:539-547.

Muedeking, M. H., and W. R. Heyer. 1976. Descriptions of eggs and reproductive patterns of Leptodactylus pentadactylus (Amphibia: Leptodactylidae). Herpetologica 32:137-139.

Nascimento, L. B., U. Caramaschi, and C. A. G. Cruz. 2005. Taxonomic review of the species groups of the genus Physalaemus Fitzinger, 1826 with revalidation of the genera Engystomops Jiménez-de-la-Espada, 1872 and Eupemphix Steindachner, 1863 (Amphibia, Anura, Leptodactylidae). Arq. Mus. Nac. Rio Janeiro 63:297-320.

Neckel-Oliveira, S., and M. Gordo. 2004. Anfíbios, lagartos e serpentes do Parque Nacional do Jaú. P. 273 in S. H. Borges, ed. Janelas para a biodiversidade no Parque Nacional do Jaú: uma estratégia para o estudo da biodiversidade da Amazônia. WWF: Fundação Vitória Amazônica, Manaus, Brazil.

Oliveira Filho, J. C. de, and A. A. Giaretta. 2008. Reproductive behavior of Leptodactylus mystacinus (Anura, Leptodactylidae) with notes on courtship call of other Leptodactylus species. Iheringia Série Zool. 98:508-515.

Ortega-Andrade, H. M., J. Bermingham, C. Aulestia, and C. Paucar. 2010. Herpetofauna of the Bilsa Biological Station, province of Esmeraldas, Ecuador. Check List 6:119-154.

Perotti, M. G. 1997. Modos reproductivos y variables reproductivas cuantitativas de un ensamble de anuros del Chaco semiárido, Salta, Argentina. Rev. Chil. História Nat. 70:277-288.

Ponssa, M. L. 2008. Cladistic analysis and osteological descriptions of the frog species in the Leptodactylus fuscus species group (Anura, Leptodactylidae). J. Zool. Syst. Evol. Res. 46:249-266.

Prado, C. P. de A. P., and C. F. B. Haddad. 2003. Testes size in Leptodactylid frogs and occurrence of multimale spawning in the genus Leptodactylus in Brazil. J. Herpetol. 37:354-362.

Reading, C. J., and G. M. Jofré. 2003. Reproduction in the nest building vizcacheras frog Leptodactylus bufonius in central Argentina. Amphibia-Reptilia 24:415-427. 
Rocha, P. C., T. L. Pezzuti, and P. C. de A. Garcia. 2016. Advertisement call of Leptodactylus viridis (Anura: Leptodactylidae) from Minas Gerais, Brazil. Salamandra 52:342-344.

Rodriguez, L. O., and W. E. Duellman. 1994. Guide to the frogs of the Iquitos Region, Amazonian Peru. University of Kansas Printing Service, Lawrence, Kansas, USA.

Sá, R. O. De, T. Grant, A. Camargo, W. R. Heyer, M. L. Ponssa, and E. Stanley. 2014. Systematics of the Neotropical genus Leptodactylus Fitzinger, 1826 (Anura: Leptodactylidae): phylogeny, the relevance of non-molecular evidence, and species accounts. South Am. J. Herpetol. 9:S1-S100.

Santos, E. M., and F. D. O. Amorim. 2005. Modo reprodutivo de Leptodactylus natalensis Lutz, 1930 (Amphibia, Anura, Leptodactylidae). Rev. Bras. Zoociências Juiz Fora 7:39-45.

Santos, E. M. Dos, and F. O. De Amorim. 2006. Cuidado parental em Leptodactylus natalensis (Amphibia, Anura, Leptodactylidae). Iheringia Série Zool. 96:491-494.

Savage, J. M. 2002. The amphibians and reptiles of Costa Rica: a herpetofauna between two continents between two seas. University of Chicago Press, Chicago, USA.

Sazima, I., and W. C. A. Bokermann. 1978. Cinco novas especies de Leptodactylus do centro e sudeste brasileiro (Amphibia, Anura, Leptodactylidae). Rev. Bras. Biol. 38:899-912.

Schlüter, A., P. Löttker, and K. Mebert. 2009. Use of an active nest of the leaf cutter ant Atta cephalotes (Hymenoptera: Formicidae) as a breeding site of Lithodytes lineatus (Anura: Leptodactylidae). Herpetol. Notes 2:101-105.

Schulze, A., and M. Jansen. 2012. One species, two strategies? Oviposition site variation in a member of the Leptodactylus pentadactylus group (Amphibia: Anura: Leptodactylidae). Stud. Neotrop. Fauna Environ. 47:183-191.

Shepard, D. B., and J. P. Caldwell. 2005. From foam to free-living: ecology of larval Leptodactylus labyrinthicus. Copeia 4:803-811.

Silva, W. R. da, and A. A. Giaretta. 2009. On the natural history of Leptodactylus syphax with comments on the evolution of reproductive features in the $L$. pentadactylus species group (Anura, Leptodactylidae). J. Nat. Hist. 43:191-203. 
Souza, M. B. de, and C. F. B. Haddad. 2003. Redescription and reevaluation of the generic status of Leptodactylus dantasi (Amphibia, Anura, Leptodactylidae) and description of its unusual advertisement call. J. Herpetol. 37:490-497.

Toledo, L. F., L. M. Castanho, and C. F. B. Haddad. 2005. Recognition and distribution of Leptodactylus mystaceus (Anura; Leptodactylidae) in the State of São Paulo, Southeastern Brazil. Biota Neotrop. 5:57-62.

Upton, K. A. 2015. Amphibian diversity in Amazonian flooded forests of Peru. PhD Dissertation, University of Kent, UK.

Verdade, V. K., M. T. Rodrigues, and D. Pavan. 2009. Anfíbios anuros da região da Estação Biológica do Alto da Serra de Paranapiacaba. P. 720 in M. I. M. S. Lopes, M. Kirizawa, and M. M. da R. F. de Melo, eds. Patrimônio da Reserva Biológica do Alto da Serra de Paranapiacaba - A antiga Estação Biológica do Alto da Serra. Instituto de Botânica, São Paulo, Brazil.

Weiler, A., K. Núñez, K. A. Wood, E. O. Lavilla, S. Peris, and D. Baldo. 2013. Família Leptodactylidae. Pp. 85-112 in Anfibios del Paraguay. Universidad Nacional de Asunción, Facultad de Ciencias Exactas y Naturales, Asunción, Paraguay.

Wells, K. D. D. 2007. The ecology and behavior of amphibians. The University of Chicago Press, Chicago, USA.

Zina, J., and C. F. B. Haddad. 2005. Reproductive activity and vocalizations of Leptodactylus labyrinthicus (Anura: Leptodactylidae) in Southearstern Brazil. Biota Neotrop. 5:1-11. 


\section{Conclusão Geral}

Se você pulou toda a tecnicalidade que recheia esta tese e tem curiosidade para saber o que descobrimos, aqui vai um resumo da ópera. Vamos começar com o Capítulo 1, cujo objetivo era testar se o ambiente sonoro no qual as fêmeas são criadas influencia a propensão à poliandria quando adultas. Para entender as causas da poliandria em um grilo australiano, separei fêmeas jovens em dois grupos. Em cada grupo, as fêmeas foram criadas em um ambiente sonoro distinto: um somente com cantos de machos muito atrativos (chamarei este grupo de 'machos de elite') e outro com cantos de machos muito e pouco atrativos (chamarei este grupo de 'machos variados'). Neste momento, você deve estar se perguntando o que faz um macho de grilo ter ou não um canto atrativo, certo? Ao contrário de aves e humanos, a atratividade do canto em grilos não está relacionada à melodia, pois os cri-cri-cris emitidos pelos machos são invariavelmente monotônicos e terrivelmente irritantes aos ouvidos humanos! Fêmeas de grilos se sentem mais atraídas por machos que se esforçam em cantar muito: quanto mais tempo um macho permanece cantando, mais sexy ele é aos ouvidos das fêmeas. Portanto, no grupo de 'machos de elite' as fêmeas cresciam ouvindo gravações somente de machos que cantavam muito e, no grupo de 'machos variados', as fêmeas cresciam ouvindo gravações de alguns machos que cantavam muito e alguns machos que cantavam pouco.

Após ficarem adultas, ofereci sequencialmente dez machos diferentes para cada uma das fêmeas em ambos os grupos. Para cada macho oferecido, fiz uma avaliação prévia do seu esforço de canto para ter uma medida de quão atrativos eles eram. Depois de muito voyeurismo animal, obtive informações detalhadas sobre a quantidade de machos aceitos por cada fêmea e também sobre a atratividade destes machos. Por fim, comparei a quantidade de machos aceitos pelas fêmeas, ou seja, o grau de poliandria no grupo de 'machos de elite' e no grupo de 'machos variados'. Minha expectativa era que fêmeas que cresceram ouvindo machos de atratividade variada teriam maior capacidade de diferenciar cantos, pois teriam "ouvidos mais apurados". Portanto, fêmeas do grupo de 'machos variados' deveriam rejeitar machos 
pouco atrativos e aceitar machos muito atrativos. Como o conjunto de dez machos oferecidos para cada fêmea era escolhido aleatoriamente, algumas fêmeas deveriam encontrar com muitos machos pouco atrativos e consequentemente copulariam pouco. Outras fêmeas, porém, deveriam encontrar com muitos machos muito atrativos e consequentemente copulariam bastante. Fêmeas do grupo de 'machos de elite', que ouviram apenas machos muito atrativos durante toda a vida, deveriam ter dificuldade em discriminar machos pelo canto e, portanto, deveriam copular independentemente da qualidade dos machos ofertados.

Ufa! Agora, vamos aos resultados. O número médio de machos aceitos foi muito similar entre fêmeas criadas nos grupos de 'machos de elite' e de 'machos variados', ou seja, o grau de poliandria não é influenciado pela experiência sonora das fêmeas durante o desenvolvimento. Em ambos os grupos a chance das fêmeas aceitarem copular com um macho foi sempre alta. Porém, de acordo como minha expectativa teórica, enquanto fêmeas do grupo de 'machos de elite' copularam com os machos independentemente de sua atratividade, fêmeas do grupo de 'machos variados' copularam preferencialmente com machos atrativos. Portanto, fêmeas do grupo de 'machos variados' foram mais poliândricas quando, entre os dez machos oferecidos a elas, havia um número alto de machos atrativos. Quando o número de machos atrativos era baixo, fêmeas do grupo de 'machos variados' foram menos poliândricas. A Figura 1 representa de forma esquemática o resultado obtido e pode ajudar aquele leitor que ainda não compreendeu totalmente o que encontramos no experimento.

Por mais surpreendente que possa parecer, o grau de poliandria das fêmeas é uma característica hereditária em várias espécies. Se uma fêmea aceita copular com muitos machos, suas filhas muito provavelmente também aceitarão copular com muitos machos. Entretanto, assim como qualquer característica biológica, o grau de poliandria não depende apenas de genes, mas da interação entre estes genes e o ambiente. De fato, sabemos que o grau de poliandria pode ser influenciado por várias características ambientais. Se existe pouca comida no ambiente e as fêmeas estão mal alimentadas, fêmeas de algumas espécies de insetos copulam mais, pois nestas espécies os machos fornecem substâncias nutritivas para suas parceiras antes ou durante a cópula. Portanto, copular mais significa ganhar mais alimento. O ambiente social 
também influencia o grau de poliandria. Em muitas espécies de animais, quando a densidade de machos é alta, o assédio sexual às fêmeas aumenta. Nesses casos, as fêmeas aceitam copular com vários machos a fim de minimizar os custos relacionados à rejeição de parceiros, tais como agressões físicas de machos frustrados. No primeiro capítulo desta tese, descobrimos outro fator ambiental que pode influenciar o grau de poliandria: a experiência sonora das fêmeas durante o desenvolvimento.

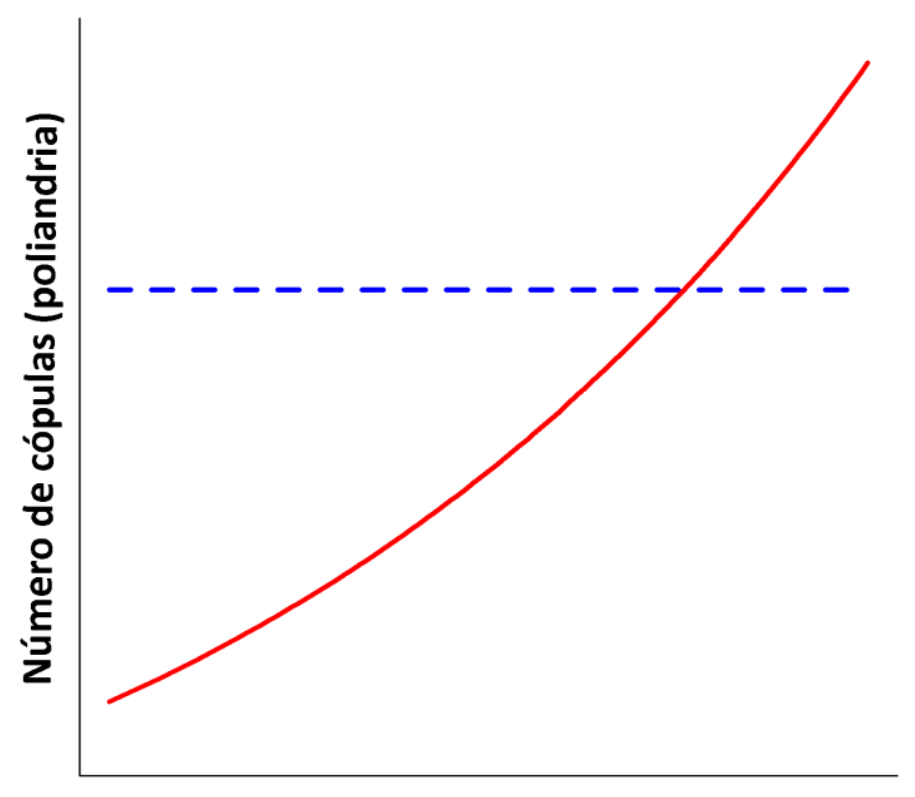

Atratividade média dos machos

Figura 1. Variação na poliandria das fêmeas criadas nos ambientes 'atrativo' (ambiente somente com cantos de machos adultos atrativos, linha azul) e 'variado' (ambiente com uma mescla de cantos de machos atrativos e pouco atrativos, linha vermelha) de acordo com a atratividade média de 10 machos que elas encontraram durante os experimentos de cópula.

Apesar do resultado obtido aqui ser muito interessante, ainda não compreendemos exatamente como a experiência sonora de uma fêmea durante o desenvolvimento pode alterar seu grau de poliandria. Com base em estudos prévios, sabemos que criar fêmeas de grilo ouvindo 'machos de elite' ou 'machos variados' faz com que alguns genes liguem e outros desliguem, o que altera o comportamento das fêmeas quando adultas. Pode ser, portanto, que a audição das fêmeas ou a capacidade delas reconhecerem machos de menor ou maior qualidade sejam alteradas pelo ligamento e desligamento de alguns genes. Independentemente dos mecanismos genéticos envolvidos, uma coisa é certa: a experiência sonora de uma fêmea nos 
estágios imaturos tem um enorme potencial de influenciar seu comportamento sexual quando adulta. Será que algo similar acontece com outras espécies que se comunicam principalmente usando sinais acústicos, tais como sapos? Será que a mudança no comportamento sexual das fêmeas também ocorre quando elas são expostas na juventude a outros tipos de sinais, tais como cheiros ou cores? No momento, não temos respostas para nenhuma dessas duas perguntas. Seria sensacional se estudos futuros investissem em respondê-las usando outros grupos de animais.

Agora vamos falar sobre os resultados do Capítulo 2, no qual exploramos as consequências da poliandria para a evolução de características morfológicas nos machos. Relembrando, o objetivo geral do segundo capítulo era investigar como o risco de poliandria furtiva (determinado pelo ambiente de oviposição) pode influenciar a evolução de armamentos masculinos. Por simplicidade, focarei em três desses armamentos: (1) espinhos no polegar da mão e (2) espinhos no peito, ambos usados para ferir rivais durante combates pela posse de fêmeas, e (3) braços musculosos nas patas anteriores, que são usados para agarrar machos durante combates e fêmeas durante o acasalamento. Nossa expectativa teórica era que, em todas as espécies que saíram da água e começaram a se reproduzir em tocas na terra, tanto a chance de um macho ser desalojado durante a cópula quanto a possibilidade de poliandria furtiva deveriam ser menores. Portanto, ao longo do tempo evolutivo, a transição água-terra seria seguida pela perda de armamentos masculinos, enquanto a transição terra-água seria seguida pelo ganho de armamentos masculinos.

Para poder testar formalmente nossa hipótese coletamos informações na literatura científica sobre a presença ou ausência dos três tipos de armamento em machos de quase todas as espécies pertencentes a uma família de rãs. Coletamos também informações sobre o local de oviposição dessas espécies, ou seja, a água ou a terra. Por fim, usamos uma árvore de parentesco das espécies estudadas que foi feita por especialistas em rãs. Essa árvore mostra quais espécies são mais aparentadas e parecidas entre si e quais são mais distantes e diferentes entre si. Usando métodos estatísticos modernos, é possível estudar a evolução dos armamentos ao longo da história evolutiva das rãs e saber se esta evolução está, de alguma forma, relacionada ao local de oviposição. Uma analogia útil para entender o funcionamento do método é 
imaginar que temos uma máquina do tempo e somos capazes de acompanhar a evolução das rãs estudadas para testemunhar se a transição água-terra ou terra-água é acompanhada pela perda ou pelo ganho de armamentos nos machos. Parece ficção científica, mas é só ciência mesmo. E depois da nossa viagem pelo tempo, vou resumir o que encontramos.

Como imaginávamos, o ambiente onde as espécies de rãs depositam seus ovos parece influenciar a evolução dos armamentos masculinos. No entanto, assim como mencionei na Introdução Geral, nem sempre os resultados que obtemos em pesquisa estão exatamente de acordo com a teoria e, muitas vezes, a natureza se mostra mais complicada do que poderíamos imaginar. Os espinhos no polegar, por exemplo, evoluem inicialmente em espécies com reprodução aquática, porém nem sempre desaparecem nas espécies com reprodução terrestre (Figura 2). O mesmo acontece com os braços musculosos, que são mais frequentes em espécies com reprodução aquática, mas não necessariamente desaparecem nas espécies com reprodução terrestre (Figura 2). Por fim, as espécies sempre tendem a perder os espinhos no peito ao longo do tempo evolutivo, independentemente de terem reprodução aquática ou terrestre. Em resumo, pelo menos dois dos três armamentos estão fortemente associados à reprodução aquática, mas a transição para a reprodução terrestre não parece torná-los "inúteis" a ponto de promover seu desaparecimento ao longo da evolução. Mas que funções as estruturas estudadas aqui poderiam ter nos machos das espécies com reprodução terrestre?

Entramos agora no campo da especulação, pois estudos comportamentais detalhados sobre as rãs que estudamos são praticamente inexistentes - seja no Brasil ou em qualquer outro país. Sabemos, porém, que mesmo em espécies que se reproduzem em tocas na terra, machos podem brigar pela posse das tocas ou para proteger a fêmea que está colocando seus ovos dentro da toca. Nesses combates, os espinhos no polegar podem ser usados como armamento e, portanto, podem ser úteis para que os machos mantenham a posse da toca ou da fêmea. Não sabemos o quão frequentes são os combates em espécies com reprodução terrestre ou mesmo se os espinhos no polegar são de fato usados nos combates entre machos de espécies com reprodução terrestre. Fica, portanto, uma dica para aqueles que se interessam em 
estudar o comportamento de rãs em campo: precisamos saber como machos de espécies com reprodução terrestre usam os espinhos nos polegares. Em particular, uma pergunta precisa ser respondida: os espinhos nos polegares são usados para a mesma função por machos de espécies com reprodução terrestre e aquática? A resposta a esta pergunta pode nos ajudar a entender os resultados que encontramos no segundo capítulo da tese.

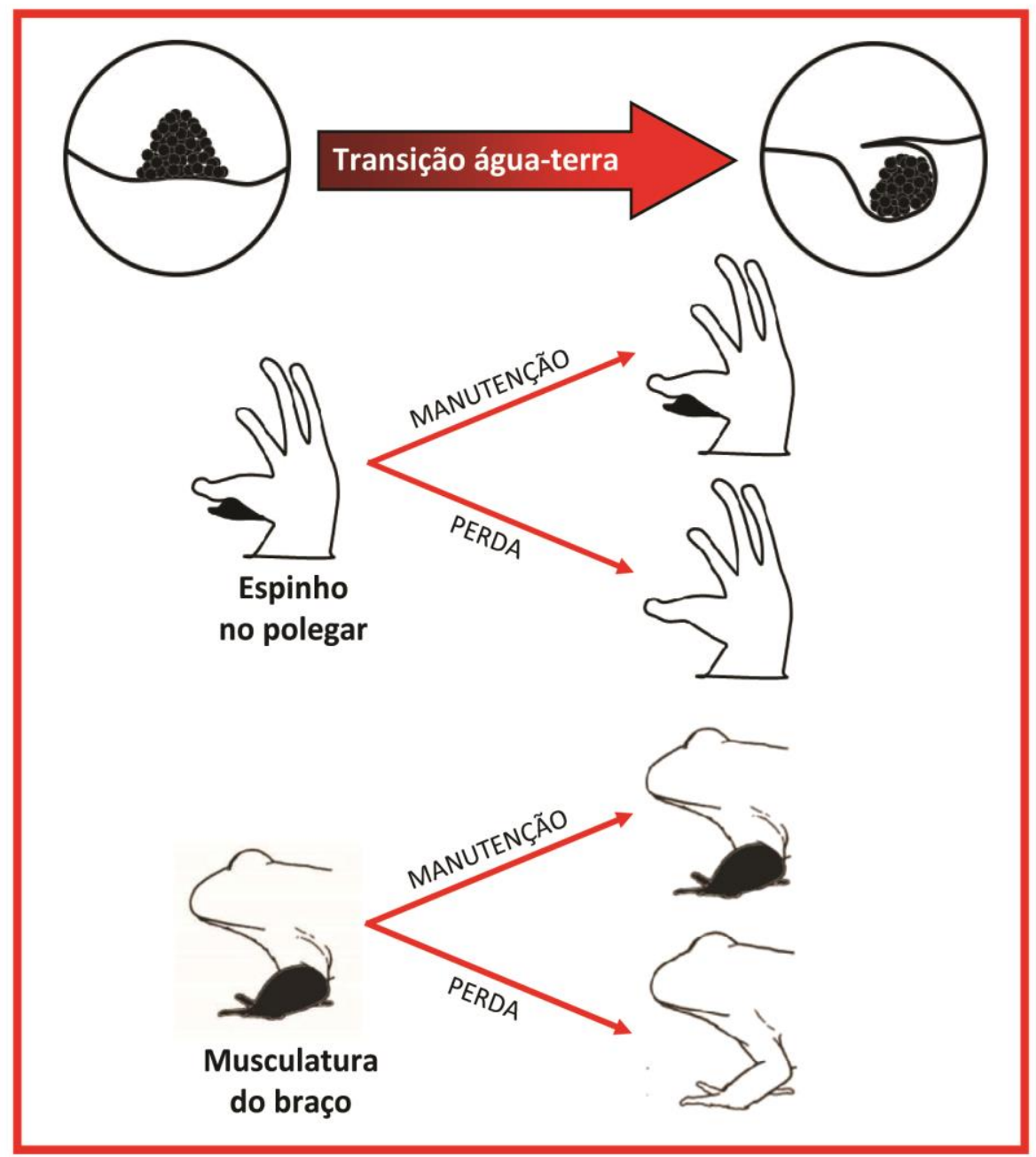

Figura 2. Esquema das mudanças evolutivas encontradas nos machos de rãs quando ocorre a transição da reprodução aquática (canto superior esquerdo) para a reprodução terrestre (canto superior direito). Diferente do que esperávamos, espinhos no polegar da mão e braços musculosos nas patas anteriores podem ser perdidos ou mantidos em machos de espécies com reprodução terrestre. É possível que essas estruturas sejam usadas na competição por tocas ou para manter as fêmeas nas tocas por mais tempo. É possível também que essas estruturas ajudem o macho a estimular a fêmea durante o acasalamento, fazendo-a liberar mais ovos. Essas duas hipóteses ainda não foram exploradas e ficam como dicas para estudos futuros. 
Adicionalmente, é razoável supor que tanto os espinhos no peito quanto os braços musculosos dos machos podem ser usados para estimular as fêmeas durante o amplexo, que é o abraço nupcial que antecede a liberação de gametas pelo casal. Se as fêmeas liberam mais gametas quando são propriamente estimuladas durante o amplexo, tanto machos de espécies que se reproduzem na água quanto machos de espécies que se reproduzem na terra teriam vantagens em ter espinhos no peito e braços musculosos. Uma possibilidade interessante para ser testada em estudos futuros é que espinhos no peito e braços musculosos tenham evoluído em espécies com reprodução aquática com uma função original de manter o agarre da fêmea em um ambiente onde o risco de um macho ser desalojado por rivais é alto. Nas espécies que mais tarde passaram a se reproduzir em tocas na terra, a função principal dos espinhos no peito e dos braços musculosos pode ter mudado para servir como uma forma de estimulação sexual da parceira. Apesar de criativa, a evolução pode ser considerada econômica (o termo chique é "parcimoniosa") e, sempre que possível, novas funções surgem a partir de características pré-existentes. Foi assim com a asa das aves - que não foram inicialmente usadas para voar - e pode ter sido assim com os espinhos no peito e os braços musculosos das rãs.

A conclusão do Capítulo 2, portanto, é que o risco de poliandria, determinado em parte pelo local onde as rãs deixam seus ovos, parece influenciar a evolução de armamentos nos machos. Os resultados que encontramos nesta tese sugerem que a seleção sexual age de forma diferente em machos de espécies com reprodução aquática e espécies com reprodução terrestre. Entretanto, o produto da seleção sexual nem sempre condiz com as expectativas teóricas. A discrepância entre a teoria e os resultados encontrados aqui pode ser parcialmente explicada por diferentes funções das estruturas masculinas estudadas. Se os tais "armamentos" masculinos podem ser usados em outros contextos, tais como em interações macho-fêmea, a transição águaterra pode gerar padrões evolutivos distintos daqueles esperados simplesmente pela ação da seleção sexual por meio de combates macho-macho. Fica claro, portanto, que observações detalhadas sobre o comportamento reprodutivo das espécies de rãs estudadas aqui são fundamentais para entendermos melhor a diversificação morfológica dos machos. 
Em conclusão, descobrimos no Capítulo 1 uma nova causa para a poliandria que está relacionada à experiência social das fêmeas durante o desenvolvimento e também durante a fase adulta. Fêmeas de uma espécie de grilo se tornam mais ou menos poliândricas de acordo com a qualidade dos machos com quais elas interagiram quando imaturas e com a qualidade dos machos com quais elas encontraram durante a estação reprodutiva. No Capítulo 2, descobrimos que o grau de poliandria das fêmeas pode ter importantes consequências para a evolução de armamentos nos machos. Entretanto, a história evolutiva das características masculinas parece ser complexa e influenciada também por outros fatores não diretamente relacionados ao grau de poliandria. Apesar de extremamente simplificado, este parágrafo de encerramento resume as principais descobertas da minha tese e dá uma ideia geral a todos os meus leitores não-biólogos do que fiz ao longo da minha jornada de quatro anos no doutorado. Como vocês devem ter percebido, eu não estava "só estudando"... 